\title{
¿HACIA UNA PRODUCCIÓN ENRIQUECIDA?: TRABAJO EN GRUPO Y RECUALIFICACIÓN EN EMPRESAS DE INGENIERÍA MECÁNICA
}

\section{Arturo Lahera Sánchez}

Profesor Contratado Doctor en el Departamento de Sociología III de la Universidad Complutense de Madrid. Dirección: Departamento de Sociología III (Despacho 2218). Facultad de Ciencias Políticas y Sociología. Campus de Somosaguas. 28223 Madrid ESPAÑA. Teléfono: +34 91394 2878. Fax: +34 91 39428 76. E-mail: alaheras@cps.ucm.es .

\section{Resumen}

El presente artículo realiza un completo estudio comparativo y empírico en cuatro talleres pertenecientes al sector de fabricación de maquinaria industrial. El análisis de los procesos de producción servirán al autor para interpretar las estructuras organizativas resultantes de las políticas de modernización utilizadas por cada uno de los centros.

\section{Palabras clave}

Producción, recualificación, organización de trabajo, polivalente

\begin{abstract}
This paper develops a comprehensive comparative and empiric study conducted in four medium size factories belonging to the industrial machinery production. The analysis of the productive processes will be used by the author to interpret the organizational structures resulted from the implementation of modernization policies in the different factories.
\end{abstract}

\section{Key Words}

Production, re-qualification, work organization, polyvalent

\section{Agradecimientos}

Para la profesora Silvia Jiménez (Universidad Pontificia Comillas), que en una década de amistad ha contado conmigo en múltiples ocasiones para ayudarme en mi devenir profesional y académico (¡Gracias!). 
— n la última década volvió a aflorar de una manera destacada en las Ciencias Sociales del Trabajo Luna reflexión sobre la posible emergencia de nuevos modelos y conceptos productivos en las empresas, es decir, una supuesta nueva articulación de principios o paradigmas organizativos para reorganizar los procesos de producción en los que se ha enfatizado la necesidad de la recualificación y participación destacada de los trabajadores y la necesaria ruptura con la vieja y tradicional división taylorista del trabajo (Boyer y Freyssenet, 1996; Durand, Stewart y Castillo, 1999), haciendo mayor hincapié en la implicación de los trabajadores en la gestión autónoma de sus puestos de trabajo. Precisamente, en la última década (1994-2000), un número destacado de empresas vascas fabricantes de máquinas-herramienta (por arranque de viruta, como tornos, fresadoras, rectificadoras y centros de mecanizado) han desarrollado y diseñado nuevas formas de gestión empresarial, habiendo comenzado a aplicar dispositivos discursivamente recualificadores que han permitido aparentemente una modificación de las formas históricas taylorizadas con las que se había fabricado (mecanizado y, sobre todo, montado) este tipo de maquinaria. Estas pretendidamente novedosas estrategias han estado orientadas por los contenidos de los políticas diseñadas conjuntamente por el Gobierno Vasco (Eusko Jaurlaritza) y la Asociación (empresarial) de Fabricantes de Máquinas-Herramienta (AFM) para reestructurar este sector tras las sucesivas crisis cíclicas que ha sufrido en las últimas tres décadas, cuyas consecuencias ha pretendido paliar esta acción pública y empresarial concertada (Programa de Competitividad del Clúster de la Máquina-Herramienta). Este programa de reconversión industrial se ha basado en propiciar el establecimiento de nuevos objetivos productivos y de nuevas formas de organizar el trabajo y de gestionar los recursos humanos que permitan a las empresas enfrentar en mejores condiciones los nuevos caracteres del mercado mundializado (AFM, 1985 y 1990; Gobierno Vasco, 1992 y 1994; SPRI, 1994): todo ello mediante una estrategia productiva en que las empresas intentan reemplazar su tradicional fabricación de máquinas-herramientas seriadas y homogéneas (tecnológicamente maduras $u$ obsoletas) por el diseño y producción de máquinas con mayores grados de adaptación 'a medida' a las necesidades de cada cliente y con avanzados dispositivos tecnológicos (controles numéricos de última generación, alta velocidad de mecanizado, diseño por cálculo de números finitos...).

Serán los resultados obtenidos en el trabajo de campo y de terreno en los talleres de cuatro empresas, Buruzagi (fabricante de tornos y rectificadoras CNC), Berritzaile (fresadoras CNC), Zuzendu (tornos CNC) y Eskulan (fresadoras convencionales y centros de mecanizado CNC), las tres primeras en Elgoibar (Guipúzcoa) y la última en Vitoria-Gasteiz (Álava), los que se emplearán a continuación para interpretar críticamente los objetivos organizativos y productivos de estas políticas de modernización y supuesta recualificación en la gestión de sus recursos humanos ${ }^{1}$.

\footnotetext{
${ }^{1}$ Se emplearon diversas técnicas de investigación, de carácter cualitativo y participativo, para acceder a los espacios y situaciones reales de trabajo de las empresas que se han seleccionado en el trabajo de campo de esta investigación: análisis del trabajo, observación participante y entrevistas en profundidad, que han permitido obtener una interpretación global sobre el origen, el desarrollo, la implantación y los resultados de las transformaciones organizativas en el diseño del trabajo humano en las empresas fabricantes de máquinas-herramienta analizadas. Se realizaron así 80 entrevistas en profundidad a organizadores de la producción, representantes sindicales y trabajadores, al tiempo que se han reconstruido 8 puestos de trabajo, tanto de mecanizado como de montaje. Durante 16 meses (de marzo de 1998 a junio de 1999), la estancia continua y permanente en los talleres de mecanizado y montaje de esas cuatro empresas de máquinas-herramienta permitieron acceder a un trabajo de campo de terreno en que se reconstruyeron: a) las nuevas formas de diseñar los puestos de trabajo, b) los objetivos empresariales a cubrir con esos dispositivos de reorganización del trabajo, c) sus contenidos y resultados reales en las condiciones de trabajo $y, d$ ) las experiencias subjetivas de los actores sociales (organizadores de la producción y trabajadores) observados y entrevistados. Las reflexiones contenidas en este artículo proceden de una reciente intensa
} 
Este cambio estructural y estratégico de fabricación de producto plantea teóricamente la necesidad de invertir en un nuevo tipo de fuerza de trabajo, en nuevos tipos de operadores o trabajadores de montaje, que sean capaces de ensamblar estas nuevas máquinas con mayor valor añadido tecnológico en condiciones diferenciadas no sólo cuantitativas, sino, sobre todo, enfatizando la calidad en el ensamblaje de sus componentes. Es por todo esto que esta reestructuración sectorial se comienza a construir sobre la propia transformación de las tareas, cualificaciones y condiciones de trabajo de los operadores, en este caso, encargados del montaje de los nuevos modelos de máquinas-herramienta, todo lo cual se expresa en concebir gerencialmente ahora a la fuerza de trabajo directa en el taller, al obrero colectivo, como uno de los recursos empresariales más valiosos: sus conocimientos del proceso de montaje, sus experiencias prácticas en la manipulación y ensamblaje de los componentes y subconjuntos de la máquina y su capacidad de solventar mediante sus métodos empíricos incidentes y problemas productivos que tan sólo los propios operadores de taller pueden detectar y resolver cualificadamente lleva a que sea necesario ahora potenciar y recualificar a los recursos humanos para poder afrontar no sólo los cambios en la incertidumbre del mercado sino, sobre todo, para poder montar los nuevos diseños de máquinas bajo criterios productivos y de calidad incrementadamente exigentes: todo ello mediante un nuevo concepto del trabajo humano que ahora es concebido como un recurso estratégico a movilizar cualificadamente (Kissler, 1994: 184), de manera que pueda adaptar sus actividades de trabajo a una mayor variabilidad de las situaciones de fabricación a afrontar en esta nueva producción a medida (Kidd, 1990: 92). Requiere invertir fuertemente en un nuevo arquetipo de operador de montaje que sea capaz de ensamblar cualificadamente y con calidad un nuevo tipo de maquinaria a través de la implantación de nuevas formas y conceptos de organización del trabajo, tales como la rotación de tareas, el trabajo en grupo y una producción con actividades integradas y flexibles (Kenney y Florida, 1988: 122).

\section{La construcción de 'operadores polivalentes de montaje': la transformación del trabajo teórico de los organizadores de la producción}

El trabajo teórico está constituido por las concepciones que los organizadores de la producción (gerentes, ingenierías y departamentos de métodos, es decir, los grupos relevantes con capacidad de toma de decisiones en las empresas) desarrollan sobre la función productiva a desempeñar por el trabajo humano (Teiger, 1994), sobre si éste es un recurso relevante o superfluo en la gestión y fluidez del proceso de producción. Según sea la orientación o el paradigma organizativo de dirección e ingenieros sobre la amplitud de las funciones de los operadores del taller se diseñarán o prescribirán tanto los objetivos a obtener en el proceso como los procedimientos y reglas que deberán seguir los trabajadores, estableciendo el nivel de sus cualificaciones y de su autonomía a la hora de desarrollar su actividad laboral (Lahera Sánchez, 2005). Precisamente, frente al paradigma organizativo con caracteres tayloristas de la organización del trabajo de montaje del modelo productivo tradicional histórico en el

revisión de una primera discusión teórica y trabajo de campo recogidos en mi tesis doctoral La emergencia de nuevos modelos productivos y la participación de los trabajadores: Diseño e implantación de conceptos antropocéntricos de producción en empresas fabricantes de máquinas-herramienta (Lahera Sánchez, 2000), dirigida por el profesor Juan José Castillo (Lahera Sánchez, 2000). 
sector de fabricación de máquinas-herramientas (Lahera Sánchez, 2005: capítulo 5), las empresas y sus organizadores de la producción introducen como dimensión estratégica en las políticas de reestructuración sectorial la construcción de un trabajo teórico (reflejado en los discursos gerenciales) centrado en enfatizar la centralidad de sus recursos humanos, de su fuerza de trabajo, como apuesta estratégica para hacer frente a las nuevas demandas de flexibilidad desde el mercado: flexibilidad que se pretende lograr mediante un uso más eficiente e intenso de las capacidades empíricas y creativas, de la inteligencia de producción, de los propios operadores de montaje: estableciendo "cómo utilizar el conocimiento de los trabajadores para el objetivo de la racionalización" (Smith, 1989: 210). Los contenidos que los organizadores de la producción pretenden acuñar en sus operadores de montaje están referidos a un trabajo teórico fundamentado en lo siguientes objetivos:

1. La consecución de la flexibilidad mediante la polivalencia: las políticas de transformación de la organización del trabajo de montaje pretenden, por parte de los organizadores de la producción de las empresas analizadas, apostar por la formación e inversión en unos operadores que puedan desarrollar su trabajo en distintos puestos y estaciones funcionales, que puedan montar toda la variedad de subconjuntos posibles que componen la máquina-herramienta y que puedan realizar su ensamblaje en cualquiera de los modelos de catálogo independientemente de su grado o nivel de complejidad: "crear una organización del trabajo donde las tareas repetitivas se eliminen y donde los trabajadores sean formados en tareas mejores y más productivas" (Brulin y Nilsson, 1999: 327):

Y que además no sólo monte las bancadas y las mesas, sino también la columna y los carenados, cuanto más mejor; porque si hay que ir a casa del cliente a solucionar algún fallo, con mandar a un montador vale y así no tendría que mandar al montador de la mesa y la bancada y al montador del otros conjuntos o además al pintor (Director de I+D. Empresa Buruzagi).

Se define así una figura de operador polivalente de montaje caracterizada por integrar en los trabajadores de montaje todos los conocimientos cognitivos, pericias manuales y tareas necesarias para poder ensamblar completamente todos los elementos que conforman cualquier modelo de máquina (o al menos varios subconjuntos), es decir, romper con la especialización tradicional de los operadores y que todos ellos pasen a convertirse en operadores polivalentes:

Que todos sean comodines [polivalentes], estás haciendo un núcleo de personas que son todos comodines y que los puedes usar en cualquier lado con garantías, solucionando los problemas y no como antes que estabas colgado de las especialidades de cada uno[especialistas] y no había manera de eliminar los cuellos de botella cuando se producían (Director de Montaje. Empresa Buruzagi).

Estos nuevos operadores polivalentes de montaje deberían ser capaces a través de su recualificación, es decir, mediante mayores conocimientos y una autonomía más amplia, de poder desarrollar cualquier puesto o estación de trabajo, de cambiar de uno a otra y de tener una imagen operativa ${ }^{2}$ completa del montaje total de la máquina, es decir, de construir una fuerza de trabajo en que todos los operadores son intercambiables entre sí (Delbridge, Turnbull y Wilkinson, 1992: 101):

\footnotetext{
${ }^{2}$ Una imagen operativa supone, en términos de las metodologías ergonómicas, representaciones cognitivas conforman un modelo interiorizado por el trabajador que le asegura una guía para su acción de forma funcional (positiva) para ejecutar correctamente su tarea; esa representación es funcional y operativa en tanto asegura la planificación y orienta la acción de los sujetos (Leplat, en Castillo y Villena, 1998: 181-195).
} 
Nos planteamos los equipos de trabajo en montaje para conseguir la polivalencia, porque nos encontrábamos que la empresa dependía de cuatro sujetos, sólo había un tío que montaba cabezales y un tío que dominaba los acoplamientos de las columnas. El de cabezales montaba cualquier tipo de cabezal, era el único que podía montar un cabezal automático, que podía ajustarlo, porque de entrada eso requiere unos conocimientos y mucha experiencia y sólo había una persona; yo me planteaba: "mañana coge una baja y ¿qué pasa? que ya no montamos cabezales en esta casa", y no puede ser, depender de esa manera de uno, pues no puede ser (Directora de Recursos Humanos. Empresa Berritzaile).

De esta forma, en los talleres de montaje estas empresas ya sólo aparecerían operadores polivalentes y no especialistas, distinguiéndose la cualificación de operadores individuales en relación al incremento continuo de sus conocimientos para realizar el montaje completo: "que los operadores adquieran más tareas, amplíen su área de competencias y que tengan iniciativas que conduzcan a mejoras en la producción y al aseguramiento de la calidad" (Brulin y Nilsson, 1999: 331):

\begin{abstract}
Lo fundamental es la polivalencia y la autonomía. Dentro de la máquina-herramienta no hay series largas, normalmente son series cortas por no decir unitarias. Hay que saber montar y fabricar diferentes modelos de máquinas; normalmente, antes cada persona estaba especializada en un modelo específico de máquina, ahora se pretende que todos sepan montar y fabricar todo (Director de Formación. Instituto de Máquina-Herramienta).
\end{abstract}

El objetivo final es que cada operario sea capaz de montar subconjuntos enteros de una máquina e incluso una máquina entera. Estamos buscando, por otra parte, con esa polivalencia, que la persona esté capacitada a hacer funciones de SAT (Servicio de Asistencia Técnica), donde una persona sale fuera y es capaz de solucionar desde el punto de vista mecánico, eléctrico y neumático, es decir, que no se estanquen en el mero montaje de una determinada pieza de un subconjunto (Director Industrial. Empreza Zuzendu).

Al mismo tiempo, la inversión y consecución de la polivalencia permitirá que los operadores de montaje puedan desarrollar un conocimiento exahustivo de las diferentes partes y procedimientos que configuran el montaje total de la máquina, pudiendo desarrollar una imagen operativa completa del ensamblaje de la máquina, lo que facilitará que los operadores puedan tanto desarrollar mejores formas o procedimientos de montaje, aplicando precisamente su ahora tan valorada inteligencia de producción cognitiva y empírica, como detectar posibles defectos de diseño que o bien dificulten la propia fabricación de la máquina entorpeciendo las operaciones de montaje ( $\mathrm{y}$ 'despilfarrando' tiempo y recursos productivos) o que puedan causar posteriormente errores de funcionamiento en 'casa del cliente' reduciendo la fiabilidad de la máquina:

\begin{abstract}
En el tipo de trabajo de aquí, hay una zona donde se va a montar una máquina y hay 6 sujetos que hacen distintas cosas sobre esa máquina: habrá gente que esté trabajando con la bancada, habrá gente que esté trabajando con el cabezal, o poniendo el cuadro, y en esa zona se termina toda la máquina, y cuando esa máquina se ha acabado se empieza con la siguiente. De lo que se trataría es de juntar 5 personas que saben distintas cosas y son capaces entre las 5 de montarte una máquina, y que el jefe de equipo vaya distribuyendo los trabajos de manera distinta, o sea dentro del equipo hay uno que sabe montar el conjunto mesa-bancada-columna y los demás no saben, pues ese que sabe montar, cada vez que le toca montar una mesa sobre la bancada, le solicite la ayuda a otra para que "vayas aprendiendo cómo se monta una mesa y una bancada, y cómo se ajustan y se acoplan, y me vayas siguiendo y, al cabo de que hayas montado 20 conjuntos conmigo, puedes hacer uno tú solo" (Directora de Recursos Humanos. Empresa Berritzaile).
\end{abstract}

Se trata, por tanto, de una concepción del trabajo teórico a acuñar en y a desarrollar por los operadores fundamentada en un paradigma organizativo que sustituye la especialización por la polivalencia (versatilidad) y al apostar por desarrollar la cualificación y la inteligencia productiva de los recursos humanos (y no sólo su polarización; Albertijn, Van Buylen y Baisier, 1999: 346-360), dimensiones ambas que se pretenden obtener mediante la implantación práctica de nuevos conceptos productivos de organización del trabajo: mediante una recualificación de las destrezas 
manuales y técnicas de los operadores de montaje (craft-skills) que faciliten el aprendizaje organizativo, es decir, la continua racionalización del proceso de trabajo:

\begin{abstract}
Antes cada uno hacía su parte, mientras que ahora ya cada persona no monta una sola y única parte en todas las máquinas, sino que monta máquinas: requiere polivalencia, conocer todo el proceso global de montaje, que aprenda varias especialidades (como mecánica, hidráulica, todo eso) según va realizando puestos y satisfaciendo tareas diferentes de la máquina (Director de Recursos Humanos. Empresa Buruzagi).

Si antes cada trabajador hacía una de las fases, ahora deberá ir haciéndose cargo de todas ellas (Director de Recursos Humanos. Empresa Buruzagi).
\end{abstract}

2. Ampliación, enriquecimiento y rotación de tareas como dispositivos para la polivalencia: para la consecución de un operador polivalente de montaje, las gerencias de estas empresas apuestan por ampliar y enriquecer los contenidos de las tareas de sus trabajadores y enfatizan la necesidad de que roten por distintos puestos y estaciones (Coriat, 1994). De esta forma, la ampliación de las tareas de los operadores de montaje se refieren a que se reintegren operaciones antes separadas en el modelo productivo tradicional de manera que se dé lugar a un ciclo de trabajo más completo y menos repetitivo (por ejemplo, que ahora un mismo montador pueda hacer por sí mismo un conjunto mayor de los montajes estructurales), pero al mismo tiempo que esas tareas reintegradas supongan un verdadero enriquecimiento del trabajo al tener un mayor contenido cualificador (una ampliación 'vertical' en términos de recualificación frente al carácter 'horizontal' de la mera ampliación), de ahí la decisión de que los trabajadores 'enriquezcan' sus cualificaciones superando su especialización en alguna de las materias de fabricación de manera que adquieran nuevos conocimientos mecánicos, hidraúlicos, neumáticos, etc, al tiempo que deberán comenzar a encargarse del desarrollo de tareas indirectas como las relativas al control y aseguramiento de la calidad o al mantenimiento de sus herramientas de montaje, incorporando así a su actividad de trabajo funciones anteriormente en manos de mandos intermedios o departamentos técnicos que delegan ahora en los propios trabajadores de taller sus atribuciones: "Una concepción más global de las tareas no presenta riesgos, sino oportunidades: las cualificaciones y la maestría profesional, incluidos los obreros, son fuerzas productivas cuya utilización es preciso promover" (Kern y Schumann, 1988: 13).

Por último, los organizadores de la producción no sólo expresan su convencimiento y reivindicación de la necesidad de diseñar tareas ampliadas y enriquecidas en sus trabajadores de montaje para poder fabricar en mejores condiciones las nuevas máquinas a medida que son su apuesta estratégica para enfrentar la incertidumbre del mercado, sino que consideran imprescindible que esas tareas se desarrollen y aprendan mediante la rotación continua de los operadores entre los diferentes puestos o estaciones de trabajo, entre las distintas tareas de ensamblaje que componen esta fase de la fabricación de la maqúina-herramienta y entre las variadas cualificaciones que componen el montaje total de la máquina ${ }^{3}$ : en definitiva, la rotación entre tareas enriquecidas y ampliadas ${ }^{4}$ como base de la polivalencia que se pretende encarnar en este nuevo tipo de operadores:

\footnotetext{
${ }^{3}$ El objetivo de la rotación se centra en fomentar un proceso de aprendizaje durante la fabricación completa de la máquina para que el operador de montaje mejore sus pericias y adquiera los nuevos conocimientos necesarios para sus tareas enriquecidas 
A nivel de montaje, se ha producido un cambio importante. Hasta no hace mucho tiempo, entre cinco y ocho años, cada persona era especialista de algo, uno era especialista en montar cabezales, otro era especialista en montar carros, otros contrapuntos, otros chapas, pero empezó a pasar que, cuando no tenía para montar cabezales, ¿qué hacía yo con el señor que me estaba montando cabezales? Eso nos llevó a establecer que no nos valía el especialista, a mí me vale aquella persona que es capaz de no ser mejor que un especialista, pero sí capaz de hacer todo tipo de montajes. Eso nos llevó a reciclar poco a poco a la gente de montaje de forma que el que sabía montar un cabezal tenía que ir pasando por diferentes departamentos para aprender el montaje de todos los elementos y no hablar ya de un especialista, sino de un montador. Al día de hoy hemos conseguido que una parte de los montadores sean capaces de montar cualquier cosa (Director de Montaje. Empresa Buruzagi).

Ahora hay un grupo de cuatro o cinco personas que montan la máquina entera, salvo alguna parte que no hemos conseguido evitar, la rasqueta y otras, que requieren su artesano, pero los grupos están ya constituidos, unos mejores que otros, y hay grupos que están perfectamente conjuntados y se ayudan totalmente, y se puede decir que la máquina entera la hace el grupo, incluso las verificaciones, salvo la electrónica. Se busca un tipo de equipo de trabajo homogéneo, potente y que sea polivalente, por supuesto (Directora de Recursos Humanos. Empreza Berritzaile).

Se trata de que todos roten y puedan desempeñar todas las operaciones de montaje, todos los procedimientos: estamos en ello ahora mismo, intentando que la gente aprenda todo lo posible. Que roten y cambien de puesto, que monten subconjuntos distintos, te permite tener mayor polivalencia y sustituir a los que falten. Incluso queremos que luego todos sepan montar diferentes modelos de máquina, tornos grandes, tornos pequeños, porque ahora casi todas las máquinas se montan de forma parecida, pocas cosas cambian y sólo esas serán las que no sepan (Director Industrial. Empresa Zuzendu).

3. La recuperación de la autonomía en el trabajo: Los principios constitutivos de la Organización Científica del Trabajo taylorista tenían como uno de sus fines principales expropiar tanto el conocimiento del taller para transferirlo a la oficina como el control detallado y minucioso de la actividad de los trabajadores a través del diseño de procedimientos imperativos de trabajo que pretendían reducir o eliminar el control obrero sobre los ritmos de producción (Taylor, 1914, 1925 y 1970): que la economía del tiempo fuera una herramienta en manos gerenciales aislada e impermeable a las regulaciones y movilizaciones del taller. Este paradigma organizativo considera que el taller debe tan sólo seguir al pie de la letra los procedimientos de trabajo diseñados por los organizadores de la producción de manera que no se deja espacio a la actuación discrecional y autónoma de los propios operadores, precisamente porque considera que la autonomía es el fundamento del control del ritmo de trabajo por parte de los trabajadores: los operadores deben ejecutar rígidamente lo establecido por la ingeniería de producción como creadora del proceso de trabajo. Frente a esta perspectiva tradicional sobre el trabajo humano, la apuesta de las empresas estudiadas en el trabajo de campo de esta investigación, a través de sus políticas de reorganización, se centra en devolver al taller su autonomía en el trabajo restringida en el modelo productivo tradicional de manera que los operadores polivalentes de montaje puedan aplicar discrecionalmente sus conocimientos y experiencias, su inteligencia de producción, para diseñar mejores métodos de ensamblado de los subconjuntos y demás componentes que conforman la máquina-herramienta; ahora es la autonomía de los trabajadores la que es teórica y discursivamente considerada por las gerencias de estas empresas como una herramienta para articular procesos de mejora continua de los procesos de fabricación, es decir, buscar colectivamente procedimientos racionalizadores de las tareas de montaje que permitan reducir los tiempos de ensamblaje, incrementar la calidad de los acoplamientos de los subconjuntos y definir formas más ajustadas o no despilfarradoras de recursos

y ampliadas (learning by doing), al tiempo que una vez que ese trabajador se ha familizarizado con sus nuevas tareas pueda mejorar los procedimientos de montaje y racionalizarlos, mejoras que se incorporarán posteriormente como nuevos procedimientos de montaje (learning by using) (Rosemberg, 1986: 121-135).

${ }^{4}$ Estas nuevas tareas teóricamente fomentan la motivación, la satisfacción, la autonomía y la cooperación de los trabajadores (Schumann, 1998): "Tareas que reten a los trabajadores y que les satisfagan" (Brandt, 1991: 3). 
(Womack, Jones y Roos, 1991; Cattero, 1996) ${ }^{5}$ : se trata de hacer la planta más transparente, es decir, de facilitar el intercambio de información y su transferencia entre departamentos, taller e ingeniería, para permitir que se compartan las experiencias y el conocimiento entre los operadores en la resolución de problemas y en la creación de procedimientos optimizadores (Camuffo y Micelli, 1999: 227) ${ }^{6}$. En todas estas dimensiones se considera ahora que, puesto que son los trabajadores de taller los agentes que desarrollan un conocimiento más cercano y de detalle del proceso de fabricación, en este caso de montaje, deben ser los propios operadores polivalentes los que se impliquen en la mejora incremental y $\sin$ fin de la racionalización de sus propias tareas y actividades, lo cual, de nuevo, sólo podrá lograrse si se les permite a los recursos humanos recualificarse para la polivalencia, rotar y enriquecer su actividad de manera que su visión completa del proceso de montaje les ayude a diseñar continuamente esas mejoras formas de obtener la producción: se trata de lograr la implicación de los trabajadores como agentes de racionalización e innovación de métodos que desempeñan ahora las funciones anteriormente centrales de los departamentos de ingeniería (Linhart, 1997 y 1990) para aprovechar "el potencial productivo del taller" (Schumann, 1998: 23).

A partir de todo esto, el reconocimiento de la centralidad del trabajo humano y de su necesaria autonomía supone fundamentalmente romper con la tradicional distinción y fractura taylorista entre concepción y ejecución puesto que ahora van a ser los propios 'ejecutantes' los encargados de concebir, mejorar y complementar los procedimientos diseñados gerencialmente, con lo que los organizadores de la producción de estas empresas delegan ahora, con la aplicación de todo este conjunto de dispositivos o conceptos productivos ya presentados, parte de las funciones que monopolizaban como técnicos y directivos: a los operadores polivalentes de montaje que se están construyendo en estas empresas se les incrementan así los espacios de decisión sobre la gestión de su propio trabajo ya que ahora no tendrán teóricamente que seguir rígida y estrictamente lo indicado por la ingeniería de producción, sino, por el contrario, ponerlo continuamente en cuestión para mejorarlo a través de la aplicación de su inteligencia de producción: "los métodos desarrollados con la participación de los trabajadores son más apropiados para el mundo real que los métodos diseñados por los ingenieros desde sus manuales e impuestos unilateralmente" (Adler, 1999: 136) ${ }^{7}$.

\footnotetext{
${ }^{5}$ La insistencia en los contenidos racionalizadores del proceso de fabricación inmanentes a estos nuevos conceptos productivos de organización del trabajo, que tienen un origen gerencial, implica que, a pesar de su insistencia en la devolución de su autonomía al trabajo humano directo, los incrementos de productividad y calidad siguen basados en el necesario control empresarial de todo el proceso (Leite, 1993: 10-11), control que ahora se basará en dispositivos participativos de los operadores, pero que sigue en manos de la ingeniería de la producción, como se presenta en detalle en Lahera sánchez (2004) con el análisis de la 'participación' como nuevo concepto productivo en las empresas fabricantes de máquinasherramienta estudiadas.

${ }^{6}$ La rotación y el enriquecimiento del trabajo no sólo suponen que los trabajadores deben ahora ser capaces de realizar un mayor número o la totalidad de las tareas de montaje, sino que los operadores deben entre ellos socializar su conocimiento, es decir, que las experiencias y conocimientos de cada uno de ellos deben hacerse 'públicos', no sólo para poder ser transmitido de unos montadores a otros, sino para que sea transparente a la propia ingeniería de producción para que ésta puede aprovechar y codificar así la inteligencia productiva del taller, lo que supone mantener mediante dispositivos organizativos innovadores y participativos la transferencia taylorista del conocimiento del taller a la oficina (Lahera Sánchez, 2004: capítulo 5; Lahera Sánchez, 2004b): "la polivalencia y la rotación han hecho que este conocimiento público y transparente sea apropiado por los departamentos de ingeniería, que lo integran en sus cálculos de tiempo y escalas" (Durand, 1999: 23).

Teóricamente se supone que la ingeniería de producción no sólo delega su función de concepción de métodos de trabajo en la autonomía creativa de los operadores de taller, sino que simultánemente se convierte en 'ayudante' de los trabajadores, facilitándoles información, resolviendo problemas productivos, es decir, como si fuera un órgano 'facilitador' del trabajo de taller y no un mero controlador de su rendimiento (Schumann, 1999: 87-90; Durand, Stewart y Castillo, 1999).
} 
La devolución de la autonomía en el trabajo a los operadores de taller se convierte así en la dimensión que subyace tanto a la ampliación y al enriquecimiento de tareas, a la rotación para la polivalencia como a la propia flexibilidad del montaje, puesto que es sólo mediante la actividad autónoma de los operadores como se puede conseguir que estos pongan ahora a disposición de la empresa sus conocimientos y experiencias construidos a lo largo de años de actividad construida y socializada culturalmente por el obrero colectivo: la cualificación, los juicios y la experiencia de los trabajadores altamente motivados contribuyen al incremento de la productividad, de ahí que los recursos humanos no sean un 'gasto' sino una 'inversión' que permite lograr la flexibilidad y la mejora continua (Kidd, 1990: 1-9): "convertir el incremento de la productividad en tarea de todos los actores de la empresa (no en una tarea exclusiva de los expertos), esperar que todos aporten soluciones a los problemas, la optimización e innovación por parte de todos" (Schumann, 1999: 84; cursiva en el original):

\begin{abstract}
Estamos intentando que la gente colabore lo máximo posible en todos los proyectos, porque entendemos que es la única fuente de mejora que tenemos y a medida que la gente se va involucrando en el tema, todo empieza a funcionar, porque si no, eso de la imposición y aquí hay que hacer así porque soy el jefe funciona según la capacidad que tengas tú de exigir y la capacidad de tu personalidad, pero al final se descojonan: tienes que perseguir los temas y hacer que la gente colabore para que si funciona, funciona para todos, para nosotros y nuestros clientes (Director de Montaje. Empresa Buruzagi).
\end{abstract}

\begin{abstract}
Se trata de que sean ahora los montadores los que se gestionen ellos mismos su propio trabajo. Reciben una fecha máxima para haber terminado la máquina y deben cumplirla, pero cómo lleguen hasta el objetivo debe ser cosa suya. Que lo hagan como quieran, pero que lo hagan bien. Para eso tienen que ser polivalentes, para distribuirse las tareas como quieran y, especialmente, para que entre todos vean de qué maneras aquello puede salir más fácilmente, en menos tiempo y con mejor calidad (Director de I+D. Empresa Buruzagi).
\end{abstract}

Al mismo tiempo, los montadores deben sugerir qué mejoras se pueden introducir en el montaje para que el trabajo sea más fácil para todos. Que le den vueltas a la cabeza entre todos para que se les ocurran cosas que mejoren continuamente el proceso. Al fin y al cabo, ellos se pasan el día en el taller, con las máquinas, tienen un montón de años de experiencia y es su oficio,tienen una posición provilegiada para darse cuenta de errores, mejoras e ideas que a los que no estamos allí se nos escapan. Eso es lo que hay que lograr, que se pongan las pilas y piensen cómo mejorarlo (Directora de Recursos Humanos. Empresa Berritzaile).

Estas tres dimensiones, la polivalencia, el enriquecimiento recualificador de las tareas y funciones de los operadores, y el fomento de la autonomía en el trabajo son las nuevas características que los organizadores de la producción pretenden acuñar en su fuerza de trabajo superando así la tradicional organización del trabajo taylorizada en el montaje, todo ello como elementos de un trabajo teórico que pretende transformar los dispositivos de gestión del trabajo para mejorar la respuesta de la empresa a los turbulentos, flexible y específicos caracteres del propio mercado, es decir, es la intervención gerencial sobre el trabajo humano, definiendo formas alternativas de enfrentar la incertidumbre del trabajo ${ }^{8}$, como se intenta enfrentar la simultánea incertidumbre del mercado, de ahí que sean los recursos humanos el eje central sobre los que se articulan las nuevas políticas de reestructuración sectorial y de su desarrollo sostenido (Brandt, 1991; Novick, 1991).

\footnotetext{
${ }^{8}$ El problema clave que deben enfrentar los organizadores de la producción para gestionar la incertidumbre del trabajo humano supone que: "El capitalista o el gerente pueden ordenar al trabajador hacer algo, pero ¿cómo pueden realmente lograr que el trabajador lo haga, y que lo haga bien y rápidamente?" (Friedman, 1977: 77). Se vincula así la conversión de la fuerza de trabajo en trabajo efectivo, la productividad, con los comportamientos laborales gerencialmente exigidos a los trabajadores: "En la relación salarial, el obrero no vende solamente su fuerza productiva, vende también su sumisión a unas normas de comportamiento" (Gaudemar, 1991: 121).
} 


\title{
2. El trabajo en grupo como técnica de reorganización productiva: la fabricación de
} máquinas-herramienta en 'puertos de montaje'

Ya desde la década de 1970, al hilo de la discusión sobre las nuevas formas de organización del trabajo, y, sobre todo, durante la década de 1990, debido a la evaluación internacional de los principios y aplicaciones de la producción ligera, el trabajo en grupo como dispositivo de reorganización del proceso de trabajo se ha convertido en una de las técnicas de gestión de los recursos humanos más debatidas, difundidas y consideradas tanto a nivel empresarial y sindical como académico en el ámbito de las Ciencias Sociales del Trabajo (Durand, Stewart y Castillo, 1999; Sandberg, 1995; Berggren, 1992). El trabajo en grupo se relaciona precisamente con las necesidades de crear una fuerza de trabajo flexible y polivalente por parte de las empresas, tal y como se analizaba más arriba, para lo cual se considera gerencialmente que la distribución de tareas de producción debe realizarse ya no exclusivamente entre operadores individuales, sino entre un conjunto de trabajadores agrupados encargados de la realización más o menos completa de un subproceso de producción, en el que todos los miembros de esa agrupación deberán aprender a desempeñar la totalidad de las tareas que lo componen mediante su rotación entre los diferentes puestos de trabajo reintegrados; todo ello para la creación y socialización de un conocimiento colectivo y completo que impregne las imágenes operativas de todos los trabajadores, para que éstos puedan elaborar diagnósticos sobre los incidentes productivos y soluciones (Troussier, 1987: 43): "personas organizadas alrededor de un conjunto de tareas, con cualificaciones complementarias, profundamente implicados y con objetivos comunes y claros" (Marx y Salerno, 1999: 154).

Precisamente, en el caso de las empresas fabricantes de máquina-herramienta estudiadas en el trabajo de campo de esta investigación, la reorganización del proceso de montaje de los componentes y subconjuntos que conforman la propia máquina se comenzará a estructurar en la segunda mitad de los recientes años noventa (1994-2000) a partir de la implantación generalizada del nuevo concepto productivo representado por el trabajo en grupo: la delegación del poder o la responsabilidad de organizar el propio trabajo autónomamente por los operadores de montaje (Lehner, 1991: 26):

\begin{abstract}
Los grupos de trabajo supone hacer equipos que te acaben una máquina, que antes no, que antes yo sólo montaba el cabezal o la caja de velocidades y sólo ponía cabezales o caja de velocidades. Ahora no, yo soy de un equipo, entre tres nos preocupamos de que esta máquina se monte, hombre, somos complementarios, uno sabe de mecánica, el otro de electrónica y deben enseñarse poco a poco unos a otros, tienen muy claro los requisitos del producto, del plazo y la calidad, y lo hacen. Esos son nuestros grupos de trabajo, tienen más información, más cualificación y más responsabilidad, pero a la vez tienen más autonomía, deciden cómo realizar el montaje según sus consideraciones. Los grupos son como minifábricas con sus inputs y outputs, tienen muy claro lo que les entra y lo que les sale y ellos se manejan como quieren. Ahora de lo que se trata es de planificarlo muy bien y que cada uno apechugue con su tema, si tú has dicho para enero, pues pon todo tu sistema para que funcione para enero y además véndeselo al eslabón siguiente con una calidad determinada, como dios manda, hay que pulsar muchas teclas. Al final es un piano que al final con la misma secuencia de teclas es un sonido distinto, porque hay personas y organizaciones que son vivas y es lo bueno que tienen, pero también es muy difícil (Director de I+D. Empresa Buruzagi).
\end{abstract}

El trabajo en grupo aparece así en estas compañías como un dispositivo o técnica de organización del trabajo que permite conseguir simultáneamente diversos objetivos gerenciales que se destacan ahora como relevantes para hacer frente a los nuevos caracteres de la incertidumbre del mercado en 
la fabricación y montaje de máquinas-herramienta a medida y con características diversificadas (Mueller, en Durand, 1999: 20-21): a) constituir una fuerza de trabajo polivalente que puede ser destinada flexiblemente a estaciones de trabajo de montaje diferenciadas; b) movilizar los conocimientos productivos de los trabajadores de forma colectiva, de manera que se transmitan entre ellos sus experiencias y que pongan a disposición del proceso de trabajo esa inteligencia de producción creada y socializada colectivamente, que es ahora considerada como un recurso clave para mejorar la producción; c) obtener mediante la propia polivalencia y la rotación entre los diferentes puestos que constituyen las tareas de ensamblaje de los trabajadores agrupados que éstos desarrollen un conocimiento holista de la totalidad de operaciones que constituyen el montaje completo de la máquina mediante una lógica cognitiva coherente de realización; d) lo cual les permitirá, también mediante la aplicación de su inteligencia de producción colectiva, diseñar 'autónomamente' procedimientos de trabajo continuamente mejorados, que puedan tanto reducir los tiempos 'gastados' en la finalización de ese montaje, como perfeccionar los resultados de calidad obtenidos; e) lograr la implicación y la participación de los trabajadores a través de los contenidos ampliados o enriquecidos de sus puestos de trabajo, que mejorarán tanto sus condiciones de trabajo como reducirán las rechazadas descualificación y monotonía de sus anteriores puestos limitados por una amplia división del trabajo; f) gestionar de forma más fluida y flexible el proceso de montaje al vincular a la fuerza de trabajo con los objetivos productivos de la empresa a través de la construcción de un nuevo consenso (reducción de los conflictos dirección/taller) mediante los cauces participativos del propio trabajo en grupo y su carácter más enriquecedor y satisfactorio.

El trabajo en grupo supone así en estas empresas rechazar los componentes individualizadores de la división del trabajo taylorista presente en el modelo productivo tradicional de montaje de las máquinas-herramienta, sustituyéndolo por una concepción que reorganiza hacia el colectivo de trabajo el proceso de fabricación (Grzyb, 1981) e incrementa la relevancia productiva de la fuerza de trabajo, de los recursos humanos, que parecen convertirse en el eje principal sobre el que organizar ahora el montaje completo de las máquinas: se sustituye la cualificación individualista tradicional por la inversión en una cualificación colectiva a movilizar (Troussier, 1987: 38), habilitando organizativa y gerencialmente un mayor espacio de maniobra para el taller sobre la toma de decisiones productivas, la ejecución de los procedimientos y la gestión del tiempo (Kern y Schumann, 1988: 201-205):

\begin{abstract}
En el caso del montaje, el montador cogía las máquinas seriadas y hacía una parte de la máquina seriada, casi como en el automóvil, sólo que es un trabajo mucho más amplio y no sólo apretar cuatro tornillos, y otro trabajador hacía otra cosa, y otro otra, y así. Ese sistema de trabajo ha ido evolucionando a favor de dar a un grupo de trabajadores la responsabilidad del montaje total de la máquina, hay un tutor, gestor, jefe de equipo y éste con unos cuantos trabajadores lo que hace es responsabilizarse del montaje de la máquina y distribuye si en un momento si le interesa más que tres hagan una operación, otros tres pasen a otra y tal. Ese es el proceso utilizado en los últimos años en las máquinas no seriadas. Como has visto en el taller, hay un jefe de equipo de tres o cuatro que se responsabiliza del montaje (Director Industrial. Empresa Buruzagi).
\end{abstract}

\footnotetext{
9 La noción de 'economía del tiempo' tiene que ver con la construcción cultural y la mercantilización empresarial de una noción del 'tiempo' (Adam, 1999) en que éste no se pasa, sino que se gasta (Thompson, 1967), de ahí que, con la asalarización del trabajo, el tiempo sea del empleador, que debe explotarlo e intensificarlo para que en el gasto de una misma unidad de tiempo se obtenga un mayor trabajo efectivo (Marx, 1979: cap. X).
} 
Pues se está intentando hacer un compendio de cosas, a la gente al final se la ha juntado en equipos de trabajo en ciertos sitios, y dependiendo del sitio entre 6 personas pues se puede montar toda la máquina de cabo a rabo, sin que tenga que pasar por los especialistas de turno (Directora de Recursos Humanos. Empresa Berritzaile).

\subsection{El ensamblado de los componentes de la máquina-herramienta en puertos de montaje}

El desarrollo de los nuevos contenidos del trabajo teórico que las gerencias de las empresas analizadas han pretendido implantar a través del trabajo en grupo se estructura a través de la configuración de células o puertos de montaje. Se organizan gerencialmente grupos de montaje que ensamblan de forma completa sus respectivas máquinas, lo que supone que el conjunto de sus miembros se encargan de realizar todas y cada una de los subprocesos o subconjuntos que componen la máquina, es decir, cada grupo de trabajo debería realizar (teóricamente) de forma completa todas y cada una de las actividades que componen el proceso de trabajo de montaje. De esta forma, cada grupo de trabajo en su puerto de montaje debe realizar tanto el ajuste y rasqueteado de las piezas, como sus montajes estructurales y los montajes adicionales, así como el montaje final con las verificaciones y embalaje definitivo de la máquina.

Las gerencias de Buruzagi, Berritzaile, Zuzendu y Eskulan han diseñado un trabajo teórico similar en relación al funcionamiento que supuestamente deberían tener sus grupos de trabajo de montaje (desde ahora referidos simplemente como grupos de montaje):

a) Organización interna del grupo y división del trabajo: 1) cada uno de los operadores que constituyen el grupo deberá conocer y desempeñar todas y cada una de las operaciones que componen tanto los subconjuntos como el ensamblaje definitivo de todos ellos en una máquina unitaria; 2) para lograr la adquisición de esos múltiples conocimientos y pericias, cada uno de los operadores tendrá que rotar temporalmente por cada uno de los puestos de trabajo de los que se compone la célula o puerto de montaje, lo que supondrá que los operadores superarán así su anterior especialización funcional característica del modelo productivo tradicional en el caso de operadores veteranos, o que deberán formarse ya inicialmente de forma polivalente desde su ingreso en el montaje en el caso de nuevos operadores; 3) la rotación por cada puesto tiene como objetivo la consecución de la polivalencia de la totalidad de componentes del grupo de montaje, es decir, obtener los operadores polivalentes de montaje o comodines alrededor de los cuales han pretendido reorganizar estas compañías el montaje de sus máquinas; 4) junto a las tareas propiamente de ensamblaje, los miembros de cada uno de los grupos de montaje son responsables del mantenimiento de sus herramientas de trabajo, de la preparación y planificación del conjunto de las operaciones necesarias para completar la máquina y, sobre todo, de asegurar y controlar la calidad de todos los subconjuntos acoplados, es decir, que el montaje total de la máquina cumpla los criterios de calidad definidos por la ingeniería de producción; 5) así mismo, puesto que la calidad constituye la apuesta estratégica de estas empresas para enfrentar los nuevos caracteres de la incertidumbre del mercado, los componentes de los grupos de montaje deberán desarrollar en cada uno de los puestos 
por los que roten, tanto individual como colectivamente, procesos de mejora continua que mejoren la propia calidad y simultáneamente contribuyan a reducir los tiempos de producción:

\begin{abstract}
Se trata de desarrollar la capacidad de trabajar en equipo, que no es ninguna tontería, porque el comodín que resolvía todos los problemas él solo se ha acabado: ahora tienes que entrar a formar parte de un grupo, e igual hay uno que domina la neumática y tú no dominas la neumática, pero esa capacidad de trabajar en equipo es muy importante. Lo que es fundamental es una capacidad de renovarse y actualizarse permanente, y no cabe decir que no, te quedas obsoleto en seis meses (Director Industrial. Empresa Buruzagi).
\end{abstract}

\begin{abstract}
Hacemos un pacto, nos ponemos de acuerdo en los plazos y nos ponemos de acuerdo, en cada pedido que viene, en cuáles son los elementos que podemos lanzar con unas fechas predeterminadas y qué elementos tienen proyecto nuevo. Tienes que estar continuamente pensando en qué puedes mejorar para ser mejor que el de al lado, porque si el de al lado mejora te puede quitar pedidos y tú no tener nada que fabricar. Nosotros no nos podemos dormir, el día que nos durmamos ya hemos perdido, porque además el mercado está siempre en ebullición, sales de una y ya estás en otra; la tecnología evoluciona y como te duermas te borran del mercado echando chispas. Tienes que espabilar (Director de Montaje. Empresa Buruzagi)
\end{abstract}

En definitiva, en estos grupos de montaje se reintegran ahora teóricamente la totalidad de operaciones, subconjuntos y tareas que en el modelo productivo tradicional se distribuían entre diferentes estaciones de trabajo con operadores individuales especializados en partes limitadas y concretas del propio proceso de montaje, mientras ahora con los grupos, como técnica o dispositivo de reorganización del trabajo de montaje, éste debe ser realizado desde el principio y hasta el final por todos los operadores que, gracias a la inversión en su polivalencia, deberían ser a medio plazo individualmente capaces de montar por sí solos una máquina completa: desarrollar una imagen holista de esta fase de fabricación de la máquina-herramienta (Badham y Jürgens, 1998: 43).

b) Autonomía y holismo: Lo que caracteriza al contenido que los discursos que configuran el trabajo teórico diseñado por los organizadores de la producción de estas empresas es que hacen girar la organización interna del grupo, su división del trabajo, alrededor del indispensable incremento de los niveles de autonomía con los que los operadores encuadrados en cada grupo de montaje deben desarrollar su trabajo: su autonomía está referida a que una vez que la empresa recibe un pedido de una máquina (especial o a medida) y la ingeniería de producción ha establecido con el cliente el plazo de entrega (normalmente de unos tres o cuatro meses), los grupos de montaje pueden planificar autónomamente sus tareas, su actividad y sus recursos, es decir, pueden decidir cómo distribuir sus tareas entre los miembros del grupo de montaje, diseñar sus propios métodos de trabajo e implantar un determinado ritmo de producción a lo largo de ese plazo temporal límite establecido gerencialmente:

Los grupos tienen autonomía para gestionar el pedido pero la fecha de entrega es sagrada (Director de Recursos Humanos. Empresa Buruzagi).

De esta manera, una vez recibida una orden de producción, los grupos de trabajo pueden decidir por sí mismos cómo desarrollar su actividad y autoorganizar su carga de trabajo y los medios y procedimientos para conseguir el montaje completo de la máquina, autogestionándose en tanto que unidad productiva, con la única limitación de que deben cumplir la fecha de entrega. Junto a esta recuperación de la autonomía productiva en el montaje, la devolución gerencial de su soberanía productiva (Kern y Schumann, 1988) o discrecionalidad sobre los ritmos y métodos de trabajo, la otra 
relevante dimensión que supone la reorganización del montaje mediante el trabajo en grupo se refiere, como refleja la propia figura de operadores polivalentes de montaje, a la apuesta gerencial de estas compañías por que sus operadores desarrollen una actividad de contenidos holistas que reintegre en la cualificación de los operadores individualmente considerados todos los conocimientos y pericias necesarios que requiere el montaje completo de una máquina (Lehner, 1991: 49), que se reintegre la inteligencia de trabajo intensamente dividida por el modelo productivo tradicional de inspiración taylorista, de manera que estos operadores polivalentes sean a medio plazo capaces de montar individualmente una máquina desde el principio hasta el final (Berggren, 1992: 12-13 y 150186):

\begin{abstract}
Que tengan un conocimiento global de la máquina, que vean la máquina como un conjunto, no como antes en que su mundillo es el cabezal y de aquí no me saques. Ahora tiene que ver la máquina en su conjunto y saber que al final la máquina tiene que funcionar y que él es el responsable de que aquello funcione y nadie más. La idea antes era que ese era especialista de cabezales, y no le importaba nada el resto, ese era el especialista del carro, y cuando no había producción en lo suyo no sabías qué hacer con él y te pillaba el toro (Directora de Recursos Humanos. Empresa Berritzaile).
\end{abstract}

Que su paso por cada una de las fases le lleve a adquirir experiencias que le permitan gestionar la totalidad de la máquina para ser un profesional completo y polivalente, gracias a ese recorrido por los diferentes puestos. Sin duda, es un largo proceso temporal en el que estamos empezando a formar sobre todo a diferentes jóvenes, mientras que a los veteranos especialistas más viejos se les mantiene en sus anteriores funciones hasta que se jubilen, en que ya serán sustituidos por estos montadores completos (Director de Recursos Humanos. Empresa Buruzagi).

Esta perspectiva organizativa sobre el trabajo en grupo expresada por los gerentes, directores de recursos humanos e ingenieros de producción de estas cuatro empresas supone que su concepción teórica sobre la dinámica de funcionamiento de las células o puertos de montaje se acerca más a la definición de los grupos semi-autónomos de producción (semi-autonomous-workgroups; Sandberg, 1995) sociotécnicos (producción holista/reflexiva) que al contenido más restringido y limitado de los equipos de trabajo (teamworks) característicos de la producción ligera o toyotismo (Womack, Jones y Roos, 1991), siendo necesario presentar brevemente sus diferencias para resaltar el carácter innovador que, al menos teóricamente, tiene la reorganización productiva que se pretende estar llevando a cabo en estas destacadas empresas del sector de fabricantes de máquina-herramienta:

- Equipos de trabajo ('teamworks' en producción ligera): Trabajo en grupo; tareas con procedimientos prescritos y obligatorios; continua reducción de los tiempos de producción e intensificación de los ritmos de trabajo mediante una autonomía limitada de los operadores a través de procesos de mejora continua (kaizen); las funciones de concepción de la ingeniería de producción se delegan y distribuyen entre los miembros de los equipos que deben diseñar esos procedimientos de mejora; los resultados de esta mejora continua son apropiados por la ingeniería de producción y codificados interminablemente en nuevos procedimientos obligatorios (taylorismo participativo o democrático ${ }^{10}$ ); la mayoría de los trabajadores del equipo son polivalentes pero más en relación a una ampliación horizontal de tareas con un

\footnotetext{
${ }^{10}$ La noción de taylorismo democrático (Adler y Cole, 1995) se analiza en detalle en Lahera sánchez (2004b), en relación al supuesto o teórico contenido participativo de estos nuevos conceptos productivos, así como vinculado a las políticas y técnicas de aseguramiento de la calidad implantadas por las empresas fabricantes de máquinas-herramienta que han configurado el trabajo de campo de esta investigación.
} 
mismo nivel de cualificación (multi-tasking) que en su enriquecimiento vertical mediante la integración de tareas más cualificadas (multi-skilling); esta polivalencia se logra en un restringido rango de actividades; limitada rotación entre puestos de los operadores; integración limitada de tareas indirectas de verificación de la calidad y de mantenimiento de recursos; los equipos y sus miembros no poseen la soberanía sobre los ritmos de producción. La reorganización productiva enfatiza los objetivos económicos y el orden/disciplina en la producción (Womack, Jones y Roos, 1991; Altmann, 1995; Berggren, 1992; Durand, Stewart y Castillo, 1999).

- Grupos semi-autónomos de producción (producción reflexiva/antropocéntricos ${ }^{11}$ ): El trabajo se organiza libremente por los miembros del grupo; las tareas se definen y asignan flexiblemente por los miembros del grupo; el ritmo de trabajo es establecido por el propio grupo y negociado con la ingeniería de producción; parte de las funciones de la ingeniería de producción se distribuyen en el taller y se reducen las barreras entre estas dos instancias; fluida comunicación entre ingenieros y operadores para resolver problemas productivos; amplios niveles de autonomía entre los miembros del grupo en la gestión del tiempo, la distribución del trabajo y el diseño de procedimientos de trabajo (autogestión colectiva) y en la mejora continua; los trabajadores del grupo son en general polivalentes en tareas enriquecidas y recualificadas verticalmente; amplias dosis de rotación entre puestos de trabajo para el aprendizaje completo y holista de la totalidad de las tareas de fabricación; sustancial formación de los operadores para su recualificación; integración autónoma de tareas indirectas de verificación de la calidad, aprovisionamiento y mantenimiento; todos los operadores del grupo hacen de todo.Los objetivos de la reorganización son económicos, de reconstrucción del orden en la producción y de mejora de la calidad de vida en el trabajo de los operadores (Sandberg, 1995; Wobbe, 1991; Berggren, 1992; Durand, Stewart y Castillo, 1999).

De esta forma, a través de la definición de estos dos modelos 'típico-ideales', las concepciones que los organizadores de la producción de las empresas Buruzagi, Berritzaile, Zuzendu y Eskulan parecen reflejar en el trabajo teórico con que reestructurar los procesos de trabajo de la fase de montaje en su fabricación de máquinas-herramienta se orienta supuestamente a la definición de grupos de montaje con características similares a los grupos semi-autónomos de producción presentados, puesto que parecen hacer hincapié en diseñar procesos de trabajo mediante una producción enriquecedora que recualifica (y enriquece) el trabajo y la actividad de los trabajadores, así como los resultados productivos y económicos de las empresas (enriquece a sus propietarios y accionistas) mediante una inversión en el desenvolvimiento de los recursos humanos a medio y largo plazo (Sandberg, 1993;

\footnotetext{
${ }^{11}$ El origen de los grupos semi-autónomos de producción se remonta a las propuestas sindicales sobre nuevas formas de organización del trabajo, posteriormente recuperadas enfatizando su dimensión racionalizadora o 'productivista' por las empresas europeas más innovadoras; posteriormente se relacionaron teórica y académicamente con las experiencias de contenido antropocéntrico de las fábricas Volvo en Kalmar (1974) y Uddevalla (1993), de ahí que en múltiples ocasiones hayan
} sido denominados 'uddevallianos'. 
Cressey, 1993; Eichner, 1991) ${ }^{12}$. De esta forma una vez aprehendida y presentada la mutación en el paradigma organizativo que estructura el proceso de montaje en estas empresas o, lo que es lo mismo, las transformaciones teóricas sobre los dispositivos con los que se diseñaba el montaje de las máquinas-herramientas en el modelo productivo tradicional, a continuación se comenzará a interpretar críticamente cómo han acabado tomando forma en la práctica estas técnicas y principios organizativos supuestamente enriquecedores: se rastrearán los contenidos efectivos del trabajo real de montaje en los talleres de estas compañías, de las condiciones de trabajo de sus operadores y de los niveles de recualificación alcanzados, todo ello para evaluar hasta qué punto sus organizadores de la producción han diseñado realmente, como indican sus discursos teóricos, un proceso de montaje centrado en destacar la relevancia del factor humano a través del fomento de la autonomía de sus operadores y de su polivalencia, todo ello a través del análisis del trabajo y de la observación participante en los talleres de montaje, en las situaciones reales de trabajo: comparar el discurso con la múltiple realidad de las empresas ${ }^{13}$.

\section{Opciones organizativas en el trabajo real de montaje de máquinas-herramienta:}

\section{¿Hacia una producción reflexiva y enriquecedora?}

El trabajo real está referido a la actividad efectiva que desempeña un trabajador o conjunto de trabajadores, el obrero colectivo, en un situación contingente en la que despliega sus pericias, conocimientos y estrategias para realizar los objetivos productivos establecidos normalmente por los organizadores de la producción (Teiger, 1994; Terssac, 1996). Sólo a través del análisis de este trabajo real mediante la observación participante en los talleres de montaje de las empresas que han configurado el trabajo de campo de esta investigación se ha podido determinar tanto el contenido efectivo del trabajo de montaje diseñado gerencialmente tras las transformaciones organizativas implantadas, como si se ha producido realmente una recualificación enriquecedora de sus tareas y actividad: se trata de comprobar en la realidad de estas empresas si "la modificación de la organización del trabajo, la asignación de la totalidad del trabajo, la reducción de las diferencias jerárquicas, una cierta recualificación del trabajo industrial y las formas de participación de los trabajadores se entienden como posibilidad de una opción para poder fabricar con la máxima eficiencia productos con un alto nivel de calidad y competitividad" (Kruse, 1988: 4).

\footnotetext{
${ }^{12}$ El debate en las Ciencias Sociales del Trabajo se ha centrado en demostrar cuál de las dos opciones representadas por los equipos toyotistas o por los grupos semi-autónomos obtiene mayores incrementos de la calidad y la productividad, acusándose a la primera opción, desde paradigmas organizativos enriquecedores críticos, de lograr esos objetivos a través de la intensificación incrementada del trabajo humano (management by stress) y de su limitadísima recualificación, es decir, de no considerar la humanización de las condiciones de trabajo como interés socioeconómico destacado; obviamente, para los defensores de la segunda opción recualificadora, ésta supone una apuesta que teóricamente permite hacer compatible la racionalización con la mejora radical de las condiciones de trabajo degradadas tayloristamente (Eichner, 1991), apuesta que en términos de la Unión Europea debería implantarse para hacer frente a las economías y bloques liderados por Estados Unidos y por Japón (Comisión Europea, 1997). En este debate, se considera además que los contenidos del grupo de producción tienen un origen sindical para incrementar la recualificación y la autonomía de los operadores, mientras que los asociados a los equipos de trabajo son promovidos por las gerencias empresariales como herramienta de incremento de la productividad (Labit, 1999: 401; Gerst, Hardwig, Kuhlmann y Schumann, 1999: 392, n. 3).

13 "Sabemos bien la diferenciación qe es necesario hacer entre los principios, la filosofía enunciada por el management y lo que hacen los actores sociales" (Linhart, 1997: 18): "por los hechos los conoceréis" (Castillo, 1992: 157).
} 
A partir de todo esto, teniendo en cuenta que el trabajo en grupo se ha constituido teórica y discursivamente en el dispositivo o técnica de gestión del trabajo humano más relevante para los organizadores de la producción, a continuación se enmarcarán las cuestiones anteriores en analizar cúal ha sido también realmente el funcionamiento efectivo de este nuevo concepto productivo, sus posibles dimensiones recualificadoras y sus contenidos en relación a la emergencia o implantación de una organización del trabajo de montaje que rompa con los caracteres laboral e históricamente taylorizantes del modelo productivo tradicional. Se contrastará así el contenido real y efectivo de las prácticas gerenciales, el grado de adecuación o inadecuación de la reorganización del trabajo de montaje realmente instaurada con las imágenes o visiones téoricas manifestadas por los organizadores de la producción, reconstruyendo si se ha producido o fabricado en las situaciones reales de actividad de los operadores un trabajo humano enriquecido y recualificado que permite el desarrollo y la aplicación autónoma de la inteligencia de producción de los trabajadores o, por el contrario, se mantienen los caracteres configuradores del anterior modelo productivo tradicional taylorizado, es decir, si se ha implantado verdaderamente el 'fin de la división del trabajo' y la reprofesionalización del trabajo humano (Kern y Schumann, 1988: 368).

Se presenta a continuación, por tanto, la organización y división de la inteligencia de trabajo realmente existente en la fase de montaje de las fresadoras de la empresa Berritzaile, de los tornos de las empresas Buruzagi y Zuzendu, así como de los centros de mecanizado de la empresa Eskulan, enfatizándose el análisis de los grupos de trabajo establecidos en todas ellas, lo que permitirá evaluar hasta qué punto se han mejorado las condiciones de trabajo de los operadores de esta fase del proceso de fabricación de las máquinas-herramienta, así como las diferentes opciones organizativas implantadas por cada una de ellas.

\subsection{La inversión en una producción enriquecedora en el montaje de máquinas- herramienta: La racionalización recualificadora en los talleres de las empresas Berritzaile y Buruzagi}

A pesar de que las empresas Berritzaile y Zuzendu se diferencian productivamente en que la primera fabrica fresadoras CNC con una tecnología media-alta y la segunda fabrica tornos CNC de tecnología avanzada, ambas han reorganizado sus procesos de montaje a partir de conceptos, dispositivos y prácticas muy similares, que permiten analizarlas conjuntamente en relación a los nuevos contenidos que sus organizadores de la producción han adscrito $u$ otorgado al trabajo humano como factor relevante en la fabricación de sus máquinas-herramienta. De esta forma, a continuación se presentará e interpretará cómo se ha transformado efectivamente el proceso de trabajo de montaje, para pasar a evaluar la estructura y funcionamiento real de los grupos de montaje implantados, y terminar completando este análisis con una caracterización crítica del tipo de estrategia productiva en que tendencialmente se están basando estas dos empresas para enfrentar actualmente y en el futuro la incertidumbre del mercado. 


\subsubsection{Un montaje holista y reflexivo en puertos de montaje}

El proceso de trabajo de montaje en Berritzaile y Buruzagi se inicia con la recepción de las piezas estructurales mecanizadas (bancadas, mesas, columnas, carneros, cabezales, carros, lunetas, contrapuntos, ejes, engranes, CNCs...) y el aprovisionamiento (almacenaje) del resto de los componentes de la máquina (motores, husillos, bombas de engrase, cables, carenados, telescópicas, tornillería, pasadores, guías, regletas....). Cada grupo de montaje, compuesto de entre 5-6 operadores con un jefe de grupo en el caso de Berritzaile y de 3-4 operadores con un jefe de grupo en el caso de Buruzagi, recibe las piezas estructurales y uno (Buruzagi) o dos (Berritzaile) operadores comienzan a realizar el preajuste y rasqueteado de estas piezas eliminando manualmente, con un amplio esfuerzo físico, el material sobrante de las guías mecanizadas de contacto entre las piezas que permitirán el desplazamiento de unas sobre otras. Mientras estos operadores realizan esta primera tarea de preparación de las piezas estructurales, el jefe de grupo, o un operador en que éste delega, se acerca al almacén para retirar (normalmente) de una sola vez todos y cada uno de los elementos y piecerío (no mecanizado) necesarios para el montaje completo de la máquina: todos esos componentes se sitúan en una 'jaula', es decir, es una estantería móvil en cuyas baldas se ordenan esos componentes según su función y según el subconjunto de montaje al que pertenezcan (mesa, bancada, columna, carros...) que es desplazada hasta el puerto de montaje donde se sitúa cada grupo de trabajo; en principio que cada jaula contenga la totalidad de las piezas para el montaje comienza a indicar que van a ser los propios grupos los que dispongan libre y autónomamente el uso y distribución de ese piecerío entre sus diferentes miembros y entre los diferentes puestos que conforman el puerto de montaje y en los que se sitúan los propios operadores.

Una vez que la jaula ha llegado al espacio en el taller del grupo respectivo, en el caso del montaje de las fresadoras en Berritzaile, la distribución del trabajo de montaje es realizada por el jefe de grupo que, en general, destina a dos operadores a realizar de forma completa los subconjuntos formados por el montaje de la bancada, el montaje de la mesa, el ajuste de mesa-bancada y el acoplamiento de mesa-bancada, al tiempo que otros dos operadores en otro espacio del puerto de montaje se encargan de realizar totalmente el montaje de la columna, el montaje del carro, el ajuste de columnacarro, el acoplamiento carro-columna, así como habitualmente el acoplamiento columna-bancada, destacando que todo lo referido a tornillería, herramental y piezas parecidas se encuentran almacenadas en otras estanterías fijas situadas a lo largo del perímetro del puerto de montaje de las que se surten también libre y autónomamente los operadores; mientras esto ocurre, cuatro operadores se centran dos a dos en estos dos subconjuntos (mesa-bancada, carro-columna), un operador más se dedica al montaje del carnero y su caja de velocidades, ensamblando sus ejes y engranes mecánicos, su motobomba y electroválvulas, el eje de cambio, etc., para posteriormente este mismo operador realizar el acoplamiento carro-carnero, con la alineación del husillo y su motor, etc; de esta forma, el puerto de montaje de las fresadoras en Berritzaile se divide y distribuye en cuatro puestos de trabajo, realizándose generalmente los montajes finales y la terminación de la máquina, con la colocación de telescópicas, motores definitivos, carcasas y carenados, pegatinas, 
etc., entre todos los miembros del grupo o entre aquellos que en ese momento se encuentren libres o avanzados en el montaje de otros subconjuntos, de hecho, la propia autogestión colectiva del trabajo permite que mientras unos operadores del grupo terminan una máquina, el resto puede ir empezando el montaje de una nueva unidad o de nuevos subconjuntos recibidos ('recepcionados') (Engström y Medbo, 1995: 70).

En el caso de Buruzagi, una vez que el grupo se ha aprovisionado en el almacén de todos los componentes de la máquina, la fabricación de sus tornos CNC es organizada también por un jefe de grupo que distribuye las tareas de montaje entre los operadores autónomamente; habitualmente, dos operadores se encargan del montaje del cabezal del torno, sobre el que girará la pieza a mecanizar, realizando los agujeros del sistema de engrase, la colocación de las chavetas, el ensamblaje de los ejes y engranes del cabezal, su verificación, así como la comprobación de los ruidos que emite en funcionamiento (para asegurar que respeta las normas de seguridad), mientras que una vez finalizado este montaje, estos mismos operadores se encargarán de acoplarlo ('amarrarlo') sobre la bancada de la máquina y alinear su eje respecto a las guías de la bancada; así mismo, en este mismo puesto del puerto de montaje, suelen ser esos dos operadores los que se encargan también del montaje de los componentes de las lunetas y de los contrapuntos, desde su rebarbado o rasqueteado, pasando por el ajuste de otros elementos (bulones, rodillos, tapas, cañas del contrapunto, husillos en su caso...). Simultáneamente, otros dos operadores se dedican al montaje de la bancada, al montaje de los carros y a los montajes finales: estos operadores deben nivelar la bancada del torno donde se acoplarán el resto de los componentes, colocándole posteriormente el carro longitudinal (que se desplaza paralelamente por la bancada), verificando su alineación, perpendicularidad y nivelación, junto a la de su husillo, realizando sus ranuras de engrase, al tiempo que se sitúan las reglas cónicas y se repasan los montajes (matar esquinas, rectificar carro...), así como acoplar y amarrar el carro transversal y su husillo (rodamientos, pasadores y demás), sobre el que se sitúa el portaherramientas del torno, que debe alinearse sobre la propia bancada; junto a esto, normalmente mientras uno de estos dos operadores se encarga de montar y nivelar el motor principal, planeando sus carriles y amarrándolo a la bancada, el otro operador termina la máquina al montar el contrapunto, las lunetas (si el modelo las incluye) y la torreta portaherramientas sobre la bancada, nivelándolas y alineándolas sobre ésta última. De esta forma, en el caso del montaje de los tornos CNC de Buruzagi, aparecen dos amplios puestos de trabajo en el puerto de montaje desempeñados por dos operadores cada uno, en el que unos se dedican a los montajes parciales (cabezales, contrapuntos y lunetas) y los otros dos a los montajes fundamentales de la máquina, amplias y diversificadas tareas que son distribuidas por el jefe de grupo que en muchas ocasiones suele ser uno de esos cuatro operadores.

Lo importante a destacar aquí es que la lógica de funcionamiento de estos grupos de montaje de fresadoras y tornos se caracteriza por las siguientes dimensiones: 
a) Rotación y polivalencia: Como definían los discursos de los organizadores de la producción, el trabajo teórico de transformación del proceso de montaje, en estos grupos de producción los operadores que en un momento dado o en una máquina están trabajando en el subconjunto mesa-bancada pueden a continuación en otro momento u otra máquina encontrarse ensamblando el subconjunto carro-columna, o bien realizando los montajes finales previos a la verificación y embalaje de la fresadora (Berritzaile), o pasar de montar el cabezal a realizar las diferentes operaciones de montaje sobre la bancada de los tornos (Buruzagi). De esta forma, se rompe con la especialización funcional característica del modelo productivo tradicional, ya que ahora los operadores van adquiriendo realmente polivalencias a través de la rotación entre los puestos del puerto de montaje, facilitando el desarrollo de competencias de carácter holista (Nilsson, 1995: 78-79).

b) Proceso de trabajo holista y reflexivo: El diseño del trabajo en grupo en el montaje de las máquinas-herramienta de Berritzaile y Buruzagi puede ser calificado también de reflexivo en cuanto a que los trabajadores tienen una imagen operativa o cognitiva completa de la función de todos los elementos de montaje necesarios, articulando una lógica coherente e inteligible que vincula cada uno de los componentes, con su situación física en la máquina, sus relaciones funcionales con otras piezas o subconjuntos, etc., proporcinando una especie de 'atlas de montaje' de la maqúina-herramienta de carácter holista, es decir, completo y global, que les permitirá a medio y largo plazo, a medida que se vaya incrementando la polivalencia efectiva de todos los operadores del grupo, montar coherentemente de principio a fin toda la máquina, y no sólo una parte como en el modelo productivo tradicional que hacía que para los operadores especialistas el resto de tareas de montaje que no podían organizativamente realizar no tuvieran ningún significado o sentido lógico en relación a su propio subconjunto (Sandberg, 1995: 5). Este carácter reflexivo y holista del nuevo montaje en puertos de las máquinas-herramienta está facilitando la consecución de las propias demandas de mejora continua, de la creación por parte de los grupos de 'mejores' procedimientos de trabajo para reducir el tiempo de fabricación y mejorar la calidad, ya que con esa imagen global del proceso total de montaje puede descubrir o detectar las incoherencias, incidentes y perturbaciones que los diferentes elementos entre sí, o sus defectos de diseño o fabricación, pueden ocasionar al proceso de montaje, previniéndolos y solucionándolos para mantener fluídamente la fabricación (Blomgren y Karlson, 1995: 128) ${ }^{14}$. Esta transformación ha supuesto sustituir la intensa división de la inteligencia de trabajo de montaje del modelo productivo tradicional por una reintegración global de conocimientos imprescindible para pasar de operadores rígidamente especializados a operadores polivalentes de montaje: el conocimiento total para el montaje se distribuye de manera que cada operador desarrolla y aprende mayores pericias técnicas y manuales (Ellegard, 1995: 38-39).

\footnotetext{
${ }^{14}$ El diseño de una división de la inteligencia de trabajo basada en esta reintegración holista de las tareas supone reconocer, frente al rechazo taylorista tradicional a los métodos empíricos de los trabajadores, que es necesario aprender de los conocimientos de taller y que el derecho a detectar problemas productivos y sus soluciones se traslade también al taller. 
c) Integración y enriquecimiento de tareas: Ahora bien, un incremento de la rotación y la polivalencia podría tener efectos limitados en la mejora de las condiciones de trabajo de los operadores y de su cualificación si está exclusivamente referida al desempeño agrupado de tareas descualificadas, es decir, si las tareas reintegradas en los puestos no suponen más que la adición de operaciones con un contenido cognitivo y técnico muy reducido (Kern y Schumann, 1988: 15); los únicos efectos positivos de una rotación de este tipo podría ser el incremento de la variedad y la reducción de la monotonía de la especialización en tareas parcializadas, pero no un incremento de la cualificación. Lo que caracteriza, sin embargo, al trabajo en grupo de las empresas Berritzaile y Buruzagi es, por el contrario, que la rotación por las diferentes tareas que constituyen el montaje total de la máquina en puertos se basa en el enriquecimiento vertical de las tareas puesto que los anteriores operadores especialistas desempeñan ahora no sólo un mayor número y variedad de operaciones, sino que sus contenidos y exigencias de conocimientos y pericias se han incrementado ascendentemente, debiendo desarrollar tanto funciones anteriormente indirectas como el aseguramiento y el control de la calidad, como el mantenimiento íntegro de sus herramentales, al tiempo que el avance hacia esta producción enriquecedora ${ }^{15}$, holista y reflexiva les obliga a adquirir conocimientos en diversas disciplinas (mecánica, hidráulica, neumática, electricidad...) que anteriormente en el modelo productivo tradicional estaban generalmente clausuradas para los operadores debido precisamente a su especialización funcional. Por tanto, la reintegración de tareas diseñada en la transformación de la fase de montaje en estas empresas basada en el trabajo en grupo se ha orientado a una ampliación no sólo horizontal de las operaciones de ensamblaje sino a su enriquecimiento vertical, fomentando a través de la propia rotación y la polivalencia la recualificación de los anteriores operadores especialistas que pueden ir avanzando así hacia una producción con mayores rasgos o trazos recualificadores/reprofesionalizadores.

En definitiva, el trabajo real al que han dado lugar las transformaciones productivas diseñadas por los organizadores de la producción (trabajo teórico) de estas dos empresas que han formado parte del trabajo de campo de esta investigación, todo ello mediante la implantación de nuevos conceptos productivos, ha supuesto un avance determinante hacia la construcción en el proceso de montaje de una producción enriquecedora, con tareas ampliadas y enriquecidas, con una nueva redistribución reprofesionalizadora de la inteligencia de producción entre los operadores que, como se verá a continuación, pueden gestionar con mayores e incrementadas dosis de autonomía sus propias tareas, recuperando así la soberanía sobre su trabajo eliminada gerencialmente en el modelo productivo tradicional (Ellegard, 1995: 47), orientándose en su desarrollo actual y a medio-largo plazo por un

\footnotetext{
${ }^{15}$ Una producción enriquecedora pretende unir buenos trabajos (buenas condiciones de trabajo) con el incremento de la productividad industrial, en la que, precisamente, los grupos de trabajo en puertos paralelos y tareas ampliadas y enriquecidas, es decir, trabajos de alta calidad, son la base de la racionalización que enriquece tanto el trabajo humano como a los poseedores del capital (Ellegard, 1995). Este concepto se origina en el diseño y funcionamiento de la fábrica de montaje de Uddevalla (Sandberg, 1995).
} 
trabajo humano reflexivo, holista y recualificado (Wobbe, 1991; Lahera Sánchez, 2005), lo que se acentúa al analizar en detalle la dinámica de organización y de funcionamiento de los grupos de montaje instaurados en esta fabricación en puertos.

\subsubsection{Grupos (semi)autónomos de producción}

Lo que caracteriza las transformaciones productivas implantadas en el proceso de montaje de Berritzaile y Buruzagi, junto a la relativamente elevada rotación de sus operadores por distintos puestos de trabajo para aprender y formarse en la polivalencia es que la dinámica de funcionamiento de los grupos de montaje o células que se han diseñado para realizar completamente el ensamblaje de las máquinas se orienta más a una lógica de trabajo semiautónomo de autorregulación que a estructuras de trabajo en grupo de alcance más limitado, como pueda ser la de los equipos de trabajo de la producción ligera (Wright y Edwards, 1998) ${ }^{16}$. En el caso de estas dos empresas, efectivamente son los propios operadores integrantes del grupo los que:

a) Definen y toman todas y cada una de las decisiones sobre cómo iniciar, desarrollar y finalizar el montaje de una máquina;

b) Distribuyéndose entre ellos la carga de trabajo y las tareas en que cada uno de ellos va a situarse durante el montaje de esa unidad de producto;

c) Analizan colectivamente tanto la planificación de la producción demandada gerencialmente, como los posibles problemas productivos que van surgiendo a lo largo del ensamblaje completo de los componentes de la máquina, creando entre todos, bajo la dirección del jefe de grupo, métodos de resolución de problemas a los incidentes que vayan surgiendo en ese proceso, pudiendo realizar así autónomamente la mejora continua demandada por las gerencias de estas empresas;

d) Al tiempo que, dentro del plazo de entrega máximo aceptado por el departamento comercial e industrial de la empresa hacia el cliente, el propio grupo conserva la posibilidad de establecer su propio ritmo de trabajo, pudiendo decidir si prioriza el montaje de ciertos subconjuntos, si dedica más tiempo a la revisión de la calidad según sean las demandas o accesorios reclamados por el cliente, y, lo que es más importante, el tiempo que semanalmente puede dedicar el propio grupo a la formación para la polivalencia, es decir, la selección de un periodo de tiempo de producción dentro de ese plazo comercial para que los trabajadores puedan rotar entre puestos y comenzar a adquirir los conocimientos y pericias necesarios para dominar la totalidad de las tareas necesarias para el montaje completo de la máquina.

\footnotetext{
${ }^{16}$ Precisamente, el énfasis metodológico en trazar la posible distancia entre el trabajo teórico expresado en los discursos de los organizadores de la producción y el trabajo real efectivamente diseñado en en el 'trabajo en grupo' se debe a la "naturaleza polisémica del término, relacionada con la historia del trabajo colectivo, y con la diversidad de las situaciones concretas, que plantean diferentes cualificaciones educativas, de satisfacción e implicación en el trabajo" (Durand, 1999: 4); de ahí que sea necesario acceder a los contenidos reales y al funcionamiento efectivo de los grupos de trabajo para poder evaluar hasta qué punto han implicado una modernización y reprofesionalización del trabajo humano.
} 
Es precisamente, esta regulación y autogestión de los tiempos de formación interna en el puesto la dimensión que permite enfatizar la característica clave del funcionamiento interno de los grupos de montaje de Berritzaile y Buruzagi, la recuperación de la autonomía en el trabajo de los operadores y su soberanía procedimental y temporal sobre la producción: ahora estos grupos de montaje pueden variar tanto el método como el ritmo productivo (Engström y Medbo, 1995: 70) ${ }^{17}$, basándose precisamente en que sean los operadores autónomamente los que definan cómo emplear su inteligencia de producción (y continuar reproduciéndola y reconstruyéndola) para movilizarla con el objetivo de reducir los tiempos de fabricación e incrementar la calidad de lo fabricado, pero funcionando como célula autogestionada que debe cumplir las misiones encomendadas por la ingeniería de producción pero definiendo su propio plan de actividad y sus prioridades de montaje: los operadores pueden elegir y tomar decisiones sobre el orden final de las operaciones y el consumo de tiempo (Freyssenet, 1998: 96):

\begin{abstract}
Tenemos unos manuales de montaje con los procedimientos que debemos seguir, pero que también tenemos que corregir si se nos ocurre algo nuevo que mejore el montaje. Eso sí, aquí entre todos decidimos si montar primero la parte mecánica, si empiezas por la columna y luego vas por la mesa y la bancada, si las chapas las hace uno u otro, a veces incluso empezamos por el final (Operador de grupo de montaje de fresadora $\mathrm{CNC} \mathrm{n}^{\circ} 1$. Empresa Berritzaile).
\end{abstract}

\begin{abstract}
Como ahora nosotros decidimos a qué velocidad montar la máquina, siempre teniendo un plazo que hay que cumplir para sacarla para el cliente, podemos dedicarnos a la famosa calidad: tenemos más tiempo para dedicarnos a dejar las cosas como Dios manda, vamos como nos dicen arriba que hay que dejarlas, aunque yo creo que en ocasiones los técnicos sólo dan palos de ciego. Pero eso sí, para el obrero es ahora mucho mejor, ya no tienes encima al viejo encargado que te decía la única manera en que podías hacerlo, y encima te achuchaba con los tiempos que era muy difícil sacar la prima y, sobre todo, sacar calidad: si querían calidad, tú no llegabas a la prima, con lo que la calidad no era importante para mí, lo dejaba para que colara, pero yo muchas veces sabía que aquello iba regular (Operador de grupo de montaje de torno $\mathrm{CNC}$ n². Empresa Buruzagi).
\end{abstract}

Eso sí, una de las cosas que han cambiado una barbaridad es que ahora podemos hablar entre nosotros, bueno no sólo es que nos dejan hacerlo, y no como antes que no te dejaban ni silbar, sino que nos motivan a que lo hagamos; hablar para que entre todos resolvamos problemas, veamos qué fallos salen, cómo corregirlos para que no aparezcan otra vez: plantear mejores formas de hacer el montaje, no sólo como antes que el encargado te obligaba a hacerlo como él quería y no había otra. No nos dejaban ni apoyarnos o sentarnos para hacer el trabajo: era un ordeno y mando, incluso si lo que te mandaban te impedía realmente hacer cómodo y mejor tu trabajo (Operador de grupo de montaje de fresadora $\mathrm{CNC} \mathrm{n}^{\circ} 2$. Empresa Berritzaile).

Por tanto, teniendo en cuenta tanto la estructura de funcionamiento de los grupos de montaje (producción enriquecedora u holista), como la amplia autonomía de que gozan los miembros de cada grupo en la gestión de sus relaciones internas y externas, la transformación del trabajo de montaje en Berritzaile y Buruzagi se basa en la aplicación generalizada de una interpretación del trabajo en grupo de carácter enriquecido y recualificante, no sólo por estar orientada a la recualificación del trabajo humano, sino porque éste es el factor fundamental de regulación y gestión de las tareas de montaje, en las que los grupos tienen amplia libertad en la organización del trabajo (y de la rotación) (Albertijn, Van Buylen y Baisier, 1999: 346):

El trabajo es mucho menos monótono y somos los que estamos en el grupo los que decidimos cómo hacer las cosas. Estamos más contentos, vamos más a nuestro aire y, los de arriba lo saben porque no son tontos, si el obrero está contento, mejora para la empresa, producimos más y mejor, con más calidad, eso está claro (Operador de grupo de montaje de torno CNC n¹. Empresa Buruzagi).

\footnotetext{
${ }^{17}$ En una producción enriquecedora el principio básico de organización debe ser el contenido del trabajo, no el tiempo: el trabajador controla un trabajo que tiene sentido y que no está detalladamente constreñido por factores de tiempo, como en el caso del cronometraje y el trabajo a prima del modelo productivo tradicional (Nilsson, 1995: 76-77).
} 
Después de los cambios, somos como 'Juan Palomo': nosotros nos lo guisamos y nosotros nos lo comemos. Nos gestionamos solos, si nos faltan piezas, vamos al almacén y si hay que esperar a que las traigan, podemos cambiar el orden de montaje para no estar parados mientras nos lo traen; o empezar por un lado o por otro. Tenemos más cosas en las que pensar y hacer: lo importante es que la máquina salga en su tiempo y con los criterios que nos exigen, pero nosotros sólo decidimos cómo queremos hacerlo, y yo lo distribuyo entre los compañeros del grupo (Jefe de grupo de montaje de fresadora $\mathrm{CNC} \mathrm{n}^{\circ} 1$. Empresa Berritzaile).

Para mí ha supuesto una mejora, ya no tienes a los encargados de la vieja guardia que eran de los del látigo, puedes discutir con el encargado de taller y, sobre todo, con tu jefe de grupo, que es uno como tú; se puede hablar, discutir para ver cómo mejorar entre todos y sacar la empresa adelante, que es de todos, ¿no? Llevas tu propio ritmo, dependes más de ti mismo, pero también de los compañeros para que te echen una mano y te enseñen lo que tú no sabes y tú a ellos igual, nosotros decidimos cómo va el asunto. De hecho, creo que podríamos ir más aprisa en muchas ocasiones, pero no nos compensa porque tendríamos que cobrar más y no hay manera. Rindo lo que creo que la empresa se merece por el sueldo que me pagan [aparece así un evidente fenómeno de frenado que indica la permanencia del conflicto tradicional entre capital y trabajo: Lahera Sánchez, 2000: capítulo 4] (Operador de grupo de montaje de torno $\mathrm{CNC} \mathrm{n}^{\circ} 2$. Empresa Buruzagi).

Sin embargo, es imprescindible destacar que el fin último, manifiesto y latente, de estas transformaciones implantadas en estas dos empresas se centran en la racionalización productiva y económica del funcionamiento de la empresa y no explícitamente en la mejora de las condiciones de trabajo (su humanización) de los operadores, lo que no hace sino enfatizar que tanto el enriquecimiento del trabajo y su gestión en grupos serán gerencialmente defendidas siempre que mantenga la consecución de esos objetivos prioritarios, es decir, siempre que se considere que en un determinado plazo de tiempo la inversión en formación y polivalencia que requieren son productivamente rentables, ya que si no es así puede ser reconducida hacia formas más tradicionales de organizar el trabajo, como ha ocurrido, y veremos a continuación, en el caso de las empresas Zuzendu y Eskulan: el punto de vista determinante sobre la modernización del trabajo se basa en las necesidades y exigencias funcionales del éxito económico, de ahí el debate sobre el trabajo humano como 'recurso' productivo (Kruse, 1988: 54), no teniendo como objetivo explícito la mejora de la calidad de vida en el trabajo de los operadores de montaje, sino facilitar la toma de decisiones en el taller sobre la calidad, la productividad y la fiabilidad del proceso productivo (Camulfo y Micelli, 1999: 232; Cressey y Di Martino, 1991: 187).

\subsection{Una definición restringida y conservadora del trabajo en grupo en los talleres de montaje de las empresas Zuzendu y Eskulan}

En el caso de las empresas Zuzendu y Eskulan, el proceso de racionalización al que han conducido las imágenes teóricamente modernizadoras de las condiciones de trabajo y reprofesionalizadoras de las cualificaciones de sus operadores se ha desarrollado en una forma contrapuesta al de las experiencias que se acaban de analizar. También en este caso Zuzendu fabrica tornos CNC de tamaños mediano y grande mientras que el taller de montaje de Eskulan se dedica a la fabricación de centros de mecanizado CNC de pequeño y mediano tamaño. La fabricación de tornos de Zuzendu permite analizar comparativamente su desarrollo organizativo tras las transformaciones con la propia experiencia de Buruzagi analizada anteriormente, mientras que la similitud en el montaje de fresadoras CNC y centros de mecanizado CNC (que son en términos de diseño una fresadora con intercambiador de herramientas) facilita así mismo comparar lo ocurrido en Eskulan con lo ya presentado de Berritzaile, comparaciones que permiten obtener una imagen ampliada y detallada de 
cómo las diferentes empresas que han configurado el trabajo de campo de esta investigación han construido dispositivos coherentes de racionalización contingentes a su propia trayectoria y características, de manera que cada una de ellas, a partir de un trabajo teórico de contenidos supuestamente recualificantes y enriquecedores similares, ha desarrollado formas de organizar el trabajo de montaje diversificadas y diferentes, con resultados contrapuestos en la situación de las condiciones de trabajo y de cualificación de sus operadores.

Al igual que se ha hecho al evaluar las transformaciones productivas de Buruzagi y Berritzaile, se rastreará cuáles han sido los significados reales que los organizadores de la producción de Eskulan y de Zuzendu han otorgado en sus prácticas organizativas a su apuesta teórica por la reestructuración del trabajo de montaje de sus talleres alrededor del trabajo en grupo y de la construcción de la polivalencia en sus operadores: se trataría de acceder al sentido o significado práctico que han otorgado efectivamente en las situaciones reales de trabajo a esos dos conceptos productivos, todo ello para comprobar los resultados que han sido diseñados sobre las condiciones de trabajo de sus operadores.

\subsubsection{Una interpretación limitada y 'tradicional' de la polivalencia}

La reorganización del trabajo de montaje en los talleres de las empresas Zuzendu y Eskulan ha seguido un desenvolvimiento práctico similar centrado en incrementar de forma muy restringida la polivalencia de sus trabajadores especialistas. El proceso de fabricación se ha diseñado asignando la fabricación completa de una máquina a un grupo de montaje compuesto de 2-3 operadores en el caso de la fabricación de tornos y de 4-5 operadores en el ensamblado de los centros de mecanizado, tan sólo existiendo un jefe de grupo en el primer caso de Zuzendu, pero no en el de Eskulan; cada grupo de montaje se sitúa en un puerto donde se irán acoplando sucesivamente las diferentes piezas estructurales y el resto de componentes de la máquina sucesivamente, estando dividido ese puerto en el caso del ensamblaje de los tornos en tres puestos de trabajo, montaje de la bancada (mecánica, husillos, motores, engrase...), montajes parciales (montaje de los componentes del cabezal, lunetas y contrapuntos, y acoplamiento cabezal en máquina), y montaje de carros y acoplamiento de lunetas y contrapuntos (longitudinal, transversal, husillos...), mientras en el caso de los centros de mecanizado de Eskulan se han establecido también tres puestos de trabajo, montaje de mesa-bancada (montaje, ajuste y acoplamiento), montaje de columna y cabezal (montaje, ajuste y acoplamiento) y montaje de carenados. Cada grupo recibe de almacén una jaula con la totalidad de las piezas necesarias para montar completamente la máquina, poseyendo cada operador una mesamóvil de trabajo en que guarda sus herramientas, así como a lo largo del taller se sitúan estanterías con la tornillería y otro herramental necesario para el montaje.

Hasta aquí, esta distribución en estaciones o puestos dentro del puerto de montaje es muy similar a la implantada en las experiencias anteriormente estudiadas de Berritzaile y Buruzagi, sin embargo, su diferencia radical estriba en la organización y distribución del trabajo entre los operadores del grupo 
de montaje. En estos casos de Zuzendu y Eskulan la clave comparativamente diferenciadora reside en que los operadores son destinados a cada uno de esos puestos y son mantenidos allí indefinidamente, es decir, no pueden rotar entre los puestos que constituyen el montaje total de la máquina, no varían o cambian entre ellos, ni, por tanto, adquieren los conocimientos y pericias necesarios para saber a medio plazo montar de forma holista la totalidad de la máquina: efectivamente, se reproduce la especialización funcional característica del modelo productivo tradicional, la fijación continua de un trabajador a un mismo y único puesto de trabajo, el estancamiento de su cualificación que sigue centrada en los contenidos parcializados establecidos por esta tradicional división de la inteligencia de producción sin rotación posible (Berggren, 1992: 129):

\begin{abstract}
El cambio es que no ha habido cambio, se monta igual que antes, el mismo sistema de siempre. Yo cojo una máquina después de que en pintura le hayan dado una imprimación y del ajuste de rasqueta, y va a montaje.Uno monta una parte, la bancada, el carro y la mesa, y haces siempre el mismo trabajo, en distinta máquina, en dos tipos de máquina que varían no mucho entre una y otra, con el mismo procedimiento y el mismo trabajo, lo mismo. Ahí no ha habido ni un cambio, el proceso de montaje que se sigue es el propio de uno en el cual llevas unos años montando, la variación que ha podido haber es mínima. Y no tiene más. A mí una máquina completa que no me manden que no tengo ni idea. Nunca he tenido acceso a todas las partes. El que monta cabezales, monta cabezales (Comité de Empresa. Empresa Eskulan).
\end{abstract}

Lo que no hacen los equipos es funcionar de forma rotatoria, para que todo el mundo sepa hacer todo el trabajo, para que con el cambio y las adaptaciones que pueda hacer uno que sabe esto y luego pueda estar en otro sitio y la perspectiva que le da ahora conocer todo el trabajo porque lo ha hecho, al rotar pueda sacar los fallos que tenga y puede implicarse más en el trabajo. Se han puesto los equipos, se han puesto los mandos poco más o menos, algunos han subido en el escalafón, pero cada uno se sitúa en un único puesto y eso no implica adaptación para nada, cada uno se pega a su sitio y no tiene más capacidad que antes, no desarrolla más su profesión: se queda atascado (Comité de Empresa. Empresa Zuzendu).

Por tanto, ni en la situación real de trabajo de Eskulan ni en la de Zuzendu, la apuesta teórica supuestamente recualificadora de los operadores manifestada discursivamente por los organizadores de la producción ha supuesto un avance definido hacia la acuñación de la polivalencia en las tareas y sus contenidos de los operadores, limitándose a la reintegración de actividades y tareas que anteriormente en el modelo productivo tradicional podían estar incluso más divididas o distribuidas por un mayor número de puestos; de esta forma, sí se ha producido una ampliación de tareas como nueva forma de organizar el trabajo, pero en mucha menor medida su enriquecimiento puesto que las tareas reintegradas siguen teniendo un nivel de especialización y cualificación horizontalmente similar (incluso en términos de las disciplinas mecánicas, hidraúlicas, etc., de las que forman parte). De hecho, esta ampliación de tareas ha permitido a los operadores, paliar a través de la adición de tareas anteriormente separadas, la anterior monotonía y rutina de sus puestos de trabajo en el modelo productivo tradicional, pero no incrementar decididamente su cualificación al mantenerse fijados el puesto al que han sido organizativamente designados: si se quiere el único avance (limitadamente) 'modernizador' supone que se ha reproducido la especialización productiva del modelo tradicional de los operadores pero en tareas más amplias y variadas, pero no necesariamente más cualificadas. En este sentido, no se han producido diferencias destacables entre el modelo productivo tradicional y la concreción final práctica de los teóricamente nuevos conceptos productivos de organización del trabajo del montaje, destacando que la sustitución de la línea de montaje por los puertos de montaje no indica nada, no supone la modernización de las condiciones 
de trabajo, como en estos dos casos, puesto que se mantiene una misma lógica o paradigma organizativo taylorista para la división y distribución de la inteligencia de trabajo:

\begin{abstract}
Se nos dijo lo de los grupos de trabajo, la mejora continua y esas cosas, pero sólo teóricamente porque abajo en el taller no se ha hecho nada. Nos dijeron que se iban a hacer unas células de montaje, para trabajar en grupo, que cada ve iba ser uno más responsable, un jefe de grupo elegido por todos los compañeros para ver y discutir las pegas y cómo se podría mejorar tanto el montaje como la máquina en sí, pero sólo teóricamente decirlo, porque en la práctica, no se ha hecho nada (Comité de Empresa. Empresa Eskulan).
\end{abstract}

Casi todos seguimos siendo especialistas, no hay apenas polivalentes o comodines: ni rotamos, ni aprendemos (Comité de Empresa. Empresa Eskulan).

Así mismo, lo interesante es destacar no sólo que el contenido modernizador del trabajo teórico de los organizadores de la producción no se corresponde con los contenidos tradicionales del trabajo real implantado en sus talleres (es decir, comprobar que del dicho al hecho va mucho trecho), sino que en estos casos es necesario destacar que el sentido que los ingenieros, gerentes y mandos intermedios de Eskulan y Zuzendu otorgan al concepto 'polivalencia' tiene unos contenidos diferentes al sentido habitual (académico e industrial) con que se emplea esta nueva forma de organizar el trabajo. Sobre todo en Eskulan, la polivalencia va asociada no a que los operadores puedan rotar entre puestos diferentes con distinto nivel de cualificación, sino que puedan rotar entre diferentes puertos de montaje o modelos de máquina pero siempre en el mismo puesto de trabajo o cualificación, es decir, en este caso, la polivalencia se refiere a que en el taller existan varios operadores especializados en una tarea para que roten entre sí o, si se quiere, realmente este sentido otorgado no tiene nada que ver con la propia polivalencia, lo que no hace sino enfatizar la reproducción del modelo productivo tradicional en estas dos experiencias, lo cual queda también acentuado, como se analizará en breve, por los contenidos y dinámica de funcionamiento que se ha construido en el trabajo en grupo aplicado en estas empresas:

Que cada uno se sitúe sólo en su tarea, de dos en dos para que sean sustituibles, que no haya sólo una persona que haga las cosas. Eso sí, rotan dentro de una misma tarea, de un tamaño de máquina a otro, pero no de una tarea a otro tipo de tareas. La polivalencia es demasiado costosa (Encargado de montaje tornos CNC. Empresa Zuzendu).

Sí, la nueva idea de los grupos está dando resultados. La usamos para formar a la gente; ponemos a dos operarios juntos y van aprendiendo el montaje de su parte. La idea es que luego, una vez que hayan cogido la mano, cada uno siga en un puesto individual, sin necesidad de que sean dos, sólo si necesitan ayuda en alguna operación. ¿La polivalencia? Claro, soy el más interesado en que sean polivalentes: en que haya varios que sepan el mismo puesto para cubrir bajas (sic). No, no que roten entre diferentes puestos, sino que roten entre máquinas pero dentro de las mismas operaciones, de una máquina que se está montando a otra, pero no de una tarea a otra. La polivalencia no se trata de que todo el mundo aprenda hacer de todo, sino de tener a dos o tres personas más de las necesarias para cada tarea y que puedan sustituirse entre sí (Encargado del montaje de centros de mecanizado. Empresa Eskulan).

En definitiva, en el caso de estas dos empresas, las prácticas o conceptos de reorganización del trabajo implantados en sus talleres de montaje han supuesto en términos de diseño del proceso de fabricación de la máquina-herramienta la reproducción de las características del modelo productivo tradicional, manteniéndose la especialización funcional de los operadores y su imposibilidad de adquirir nuevas cualificaciones enriquecidas al haberse clausurado la posibilidad de la rotación de los trabajadores por la totalidad de los puestos de trabajo, con lo que estos no han podido desarrollar un conocimiento global y holista sobre el montaje completo de la máquina, tan sólo habiéndose 
producido avances de consecuencias limitadas en la mejora de las condiciones de trabajo de los operadores al haberse ampliado las tareas de los operadores mediante la integración de tareas anteriormente separadas en un único puesto de trabajo, lo que ha permitido reducir la monotonía característica del modelo productivo tradicional, que en lo demás sigue siendo dominante en estas dos empresas.

\subsubsection{La ausencia de trabajo en grupo en los 'grupos de montaje'}

Puesto que una real y amplia polivalencia no se ha producido en la reorganización del trabajo de montaje de Zuzendu y Eskulan, queda preguntarse hasta qué punto los grupos de montaje diseñados en sus talleres pueden considerarse como tales, es decir, si realmente se ha producido una generalización del trabajo en grupo o si bajo esa denominación general se justifican discursivamente prácticas de carácter tradicional. Como se ha señalado, en los grupos de montaje de estas dos empresas los operadores están finalmente especializados en los diversos puestos o estaciones que componen el puerto de montaje, con lo que no existe rotación entre puestos y cualificaciones por parte de los operadores, con lo que una de las dimensiones fundamentales del trabajo en grupo está ausente en estos grupos de montaje, tanto en términos de la más limitada modernización de los equipos de trabajo de la producción ligera como de los más recualificantes y avanzados grupos semiautónomos. Simultáneamente, la distribución de la carga de trabajo ya no es decidida colectivamente por todos los miembros del grupo, sino que depende de las indicaciones del encargado del taller y de la ingeniería de producción, ya que una vez lanzado un pedido al taller los miembros del grupo simplemente comienzan a realizar las tareas en que se encuentran especializados: de nuevo, puesto que no es posible la rotación, tampoco es factible distribuir el trabajo de manera diferente en cada ocasión, sino que siempre se realiza de la misma y única manera: cada operador en su puesto.

A esta falta de autonomía en la distribución del trabajo dentro del grupo, determinada por una división tradicional del trabajo, se añade que ni el grupo colectivamente ni los operadores individualmente han recuperado su soberanía sobre los tiempos y ritmos de producción de su trabajo, otro de los componentes del trabajo en grupo, porque se mantienen los dispositivos del cronometraje y las primas en las tareas de montaje, es decir, la autonomía del trabajo humano sigue estando controlada por la gerencia a través de una técnica taylorista intensificadora del ritmo de trabajo, que implica que, junto a a la incapacidad de los miembros del grupo de definir y distribuir las tareas a realizar, tampoco pueden gestionar colectiva y discrecionalmente los tiempos de producción, debiendo, de nuevo, establecer una regulación individual contra los cronometrajes establecidos por la oficina de métodos, que son un obstáculo organizativo para el desarrollo de su autonomía:

El tema está en que los equipos no son tales equipos, son grupos de gente que están más o menos para hacer una labor, van y la hacen: lo que se hace es buscar poco más o menos lo que había antes (Comité de Empresa. Empresa Zuzendu).

Por tanto, los grupos de montaje diseñados e implantados por los organizadores de la producción de las empresas Zuzendu y Eskulan se caracterizan por no estar basados realmente en ningún tipo de 
trabajo en grupo: bajo la denominación 'grupos de montaje' se encarna una reproducción de la división de la inteligencia de trabajo del modelo productivo tradicional, simplemente habiéndose 'reunido' en un mismo espacio físico a los operadores individuales anteriormente dispersos a lo largo de la línea de montaje, tan sólo se han agrupado espacialmente, ya que cada uno sigue desempeñando un puesto de trabajo especializado, sin rotación, sin polivalencia, ni recualificación, tan sólo una ampliación o reintegración de tareas no necesarimente enriquecidas, al tiempo que las características fundamentales que dan contenido al trabajo en grupo tales como la autonomía colectiva, la autogestión del grupo, la soberanía sobre los tiempos y las tareas, es decir, las prácticas enriquecedoras sobre las que se puede basar una producción enriquecedora y una racionalización productiva basada en la modernización de las condiciones de trabajo y en la reprofesionalización de las cualificaciones industriales de los operadores, se encuentran cuantitativa y cualitativamente ausentes de las formas efectivas con las que estas empresas han reorganizado su trabajo de montaje:

\begin{abstract}
Realmente no se trabaja en grupo, trabajamos dos porque se hacen falta, porque hay piezas que son muy pesadas para mover, pero no se ha intentado poner trabajo en grupo. Los grupos son de dos personas y cada uno hace un trabajo, uno el carro y otro mesas, y viene otro para el cabezal. No hay cambios respecto a cómo se montaban antes las convencionales, lo único es que es más cómodo montar porque todo viene mejor y no necesitas la artesanía. Además, no soy capaz de montar entero el centro de mecanizado porque hay partes que montan otros, como los cabezales. El cabezal va aparte, además de electrónica y eléctrica (Comité de Empresa. Empresa Eskulan).
\end{abstract}

Eso no es trabajo en grupo, eso es que dos personas trabajan en el mismo sitio (Comité de Empresa. Empresa Eskulan).

No hay grupos de trabajo realmente, se empezó a estudiar la posibilidad de implantarlos por parte de la dirección de la empresa, pero no así de parte de los mandos intermedios que se oponían a cualquier tipo de cambio, de mentalidad, y luego no se ha implantado ningún tipo de trabajo en grupo, no hay nada. Eso no es un trabajo en grupo, piden opinión, pero no se toma en cuenta el parecer y el papel del encargado es exactamente el mismo. El grupo aquí es que hay varios tíos en la misma máquina, pero no más. Siempre hay proyectos, pero no concreción (Comité de Empresa. Empresa Eskulan).

Se podría hablar así de una racionalización basada en un trabajo en grupo conservador (Gerst, Hardwig, Kuhlmann y Schumann, 1999: 385) que mantiene los rasgos del modelo productivo tradicional de rasgos tayloristas; de hecho, frente a la autonomía más o menos desarrollada de las diferentes configuraciones debatidas que puede adoptar el trabajo en grupo (equipos de trabajo, grupos semi-autónomos), su capacidad de tomar decisiones productivas en el ámbito inmediato del desarrollo del trabajo directo de fabricación, en el caso de estos grupos de montaje de Eskulan y Zuzendu se puede resumir su estructura y funcionamiento diseñado gerencialmente afirmando que no deciden productivamente nada, no son 'grupos' como tales, y su gestión sigue dependiendo de la rígida jerarquización tradicional. La denominación de 'trabajo en grupo' no tiene efectivamente ningún contenido recualificador, funciona en estos dos casos como una categoría sinónima a la del histórico 'modelo productivo tradicional'taylorizado:

Aquí los grupos de trabajo no deciden nada, quién decide cómo distribuir el trabajo es el encargado y dice cómo hay que hacer las cosas.

Se deberían montar los centros completos entre todos. Nos dijeron que todos haríamos de todo y que aprenderíamos a montar la máquina entera todos. Sin embargo, nos han dividido dentro del grupo en tres puestos: unos montamos las piezas grandes con todos sus husillos, sistema de engrase, guías, y otros montan la parte de arriba, los carneros, los cabezales y su acoplamiento a la columna, mientras otros se dedican exclusivamente a los carenados y al ajuste 
con la rasqueta. Al final, aunque el trabajo es más variado, nos quedamos siempre en el mismo puesto y no nos han enseñado ni nos dejan montar la máquina entera y rotar por todas las operaciones: yo de lo que hacen los otros dos de carneros, ni idea, es una parte de la máquina que no siento mía, que me es ajena, ni tiene ningún significado para mí, no la conozco (Operador de grupo de montaje de centros de mecanizado $n^{\circ} 1$. Empresa Eskulan).

Qué va, aquí a este compañero y a mí, no nos mandan a cabezales a aprender y así conocer toda la máquina, nos hemos vuelto a especializar. La máquina entera no la sabemos montar, por mucho que nos prometieron: nos dicen que así es más rápido y que no se pierde tanto tiempo. En ese sentido, rotar sería lo bueno porque tienes que aprender cosas hasta que las dominas: esa es la clave (Operador de grupo de montaje de centro de mecanizado $\mathrm{n}^{\circ}$ 2. Empresa Eskulan).

\section{Conclusiones}

En definitiva, como síntesis y conclusión de esta investigación, en el caso de los talleres de montaje de Buruzagi y Berritzaile la emergencia de un nuevo modelo productivo se ha basado mayoritariamente en el avance decidido hacia una organización del proceso de trabajo con mayores contenidos enriquecedores, en el que el incremento de las cualificaciones a través de la ampliación, el enriquecimiento de tareas y la rotación se ha complementado con la devolución de amplias dosis de autonomía a los trabajadores, que, a través del funcionamiento gerencial diseñado en los grupos de trabajo y mediante la propia regulación colectiva de los operadores, han recuperado un mayor nivel de discrecionalidad sobre el desarrollo y gestión de su soberanía productiva, de manera que el proceso de montaje deja de 'autonomizarse' al pasar a ser gestionado discrecionalmente por el trabajo humano directo de taller.

Así mismo, esta experiencia mayoritariamente 'exitosa' a nivel de la reprofesionalización del trabajo industrial y de la mejora de las condiciones de trabajo, evidencia que estas dos empresas intentan estabilizar su fabricación y competencia en una estrategia comercial y productiva que pretende hacer frente a la incertidumbre del mercado mediante su especialización en un nicho de productos de calidad y a medida, en que la recualificación del trabajo humano, la movilización y explotación de los yacimientos de su inteligencia de producción, se han convertido para los organizadores de la producción en un nuevo paradigma organizativo recualificante en que basar sus procesos continuos de racionalización, en que la consecución de una alta cualificación de sus recursos humanos de montaje permiten incrementar los resultados productivos de esta fase estratégica en la fabricación de máquinas-herramienta, diseñando lo que parece apuntar a una 'vía alta' de desarrollo de los recursos humanos (Schumann, 1999).

Sin embargo, frente a esta estrategia de valoración a medio y largo plazo del capital basada en la modernización de los recursos humanos, las otras dos empresas analizadas, Zuzendu y Eskulan, han optado en sus procesos de reestructuración de la fase de montaje por apostar por una intensificación de la explotación del trabajo humano que reproduce o mantienen los rasgos históricamente tayloristas tradicionales del sector. A pesar de que en términos teóricos los organizadores de la producción abogaban, al igual que las otras dos empresas analizadas, en invertir en la polivalencia y el trabajo en grupo para reorganizar el ensamblaje total de las máquinas, el trabajo real efectivamente diseñado e implantado ha supuesto, por el contrario, no un avance hacia paradigmas enriquecedores de recualificación del trabajo humano, sino a la reproducción y mantenimiento con escasas variaciones de 
los caracteres de organización taylorizados del modelo productivo tradicional. A lo sumo, tan sólo se ha producido, básicamente en el taller de montaje de la empresa Zuzendu, una limitada ampliación de las tareas a desarrollar por los operadores, pero no así su enriquecimiento, puesto que no se han incrementado verticalmente los niveles de cualificación a desempeñar por los operadores, que no rotan realmente entre puestos y que siguen estando especializados en subconjuntos o partes muy concretas de la máquina, al tiempo que los contenidos y el funcionamiento efectivo de los 'grupos de trabajo' no permiten que sea ésta su denominación, ya que ni permiten la rotación, ni la recualificación, ni el desarrollo autónomo de los operadores, tan sólo habiéndose 'agrupado' espacialmente en un puerto de montaje las estaciones de trabajo anteriormente distribuidas linealmente en el modelo productivo tradicional, con lo que un trabajo en grupo recualificante como tal no se ha implantado efectivamente en estas dos empresas, que no han hecho más que reproducir bajo dispositivos y denominaciones diferenciadas los elementos caracterizadores de una amplia división de la inteligencia de producción taylorista.

En el caso de estas dos empresas, la emergencia de nuevos conceptos productivos en lo referido al proceso de trabajo de montaje no ha supuesto una verdadera y definida recualificación de sus operadores, sino, por el contrario, el mantenimiento y reproducción del estancamiento y especialización de las cualificaciones tradicionales de los montadores, todo ello velado bajo discursos teóricos de modernización empresarial que no han sido realmente implantados, desarrollando una estrategia productiva basada más en la competencia en precios de sus productos mediante la valorización a corto plazo del capital mediante la intensificación descualificante del trabajo humano, mediante la definición de una 'vía baja' del desarrollo de los recursos humanos (Schumann, 1999). 


\section{Bibliografía}

Adam, B. (1999). Cuando el tiempo es dinero. Racionalidades de tiempo conflictivas y desafíos a la teoría y la práctica del trabajo, Sociología del Trabajo, 37: 5-39.

Adler, P. (1999). Teams at NUMMI. En Teamwork in the automobile industry. Radical change or passing fashion?, Durand, J.P., Stewart, P. y Castillo, J.J. (Eds.) Londres: MacMillan Press.

Adler, P. y Cole, R.E. (1995). Designed for learning: a tale of two plants. En Enriching production, Sandberg, A. (Ed.) Aldershot: Avebury.

AFM (1985). Plan de Relanzamiento Excepcional del Sector de la Máquina-Herramienta, Donostia.

AFM (1990). Plan Sectorial de Máquinas-Herramienta, Donostia.

Albertijn, M., Van Buylen, J, y Baisier, L. (1999). Teamwork at Opel Antwerp. En Teamwork in the automobile industry. Radical change or passing fashion?, Durand, J.P., Stewart, P. y Castillo, J.J. (Eds.) Londres: MacMillan Press.

Altmann, N. (1995). Japanese work policy: opportunity, challenge or threat?. En Enriching production, Sandberg, A. (Ed.). Aldershot: Avebury.

Badham, R. y Jürgens, U. (1998). Images of good work and the politics of teamwork. Economic and Industrial Democracy, 19 (1): 33-58.

Berggren, C. (1992). Alternatives to lean production, Nueva York, ILR Press.

Blomgren, H. y Karlson, B. (1995). Assembly skills, process engineering and engineering design. En Enriching production, Sandberg, A. (Ed.). Aldershot: Avebury.

Boyer, R. y Freyssenet, M. (2000). The productive models: The conditions of profitability. Houndmills: Palgrave.

Brandt, D. (1991). Advanced experiences with APS. Concepts, strategies, experiencies. Bruselas: Comisión Europea, FAST-Monitor.

Brulin, G. y Nilsson, T. (1999). The Swedish model of lean production: the Volvo and Saab cases. En Teamwork in the automobile industry. Radical change or passing fashion?, Durand, J.P., Stewart, P. y Castillo, J.J. (Eds.) Londres: MacMillan Press.

Camuffo, A. y Micelli, S. (1999). Teamwork and new forms of work organization in Fiat's 'Integrated Factory. En Teamwork in the automobile industry. Radical change or passing fashion?, Durand, J.P., Stewart, P. y Castillo, J.J. (Eds.) Londres: MacMillan Press. 
Castillo, J.J. (1991) (Ed.). Las nuevas formas de organización del trabajo (2a Edición). Madrid: Ministerio de Trabajo

Castillo, J.J. (1994). El trabajo del sociólogo. Madrid: Editorial Complutense.

Castillo, J.J. (1997). Sociología del Trabajo. Un proyecto docente. Madrid: Centro de Investigaciones Sociológicas.

Castillo, J.J. (1998). A la búsqueda del trabajo perdido. Madrid: Tecnos.

Castillo, J.J. (1999) (Ed.). El trabajo del futuro. Madrid: Editorial Complutense.

Castillo, J.J. y Villena, J. (1998) (Eds.). Ergonomía. Conceptos y métodos. Madrid: Editorial Complutense.

Castillo, S. (1992). Todos iguales ante la ley...del más fuerte. Sociología del Trabajo, 14: 149-176.

Cattero, B. (1996). ¿Solamente despilfarro? Sobre redundancia y 'slack' en la producción ligera. Sociología del Trabajo, 27: 77-101.

Comisión Europea (1997). Libro Verde sobre Cooperación para una Nueva Organización del Trabajo. Bruselas: Dirección General V.

Coriat, B. (1994). Taylor, Ford y Ohno. Nuevos desarrollos en el análisis del ohnismo. Estudios del Trabajo, 7: 3-40.

Cressey, P. (1993). Kalmar and Uddevalla: tha demise of Volvo as an European icon. New Technology, Work and Employment, 8(2): 88-90.

Cressey, P. y Martino, V. di (1991). Agreement innovation. The international dimension of technical change. Londres: Prentice Hall.

Delbridge, R., Turnbull, P. y Wilkinson, B. (1992). Pushing back the frontiers: management control and work intensification under JIT/TQM factory regimes. New Technology, Work and Employment, 7(2): 97-106.

Durand, J.P. (1998). Is the 'better job' still possible today?. Economic and Industrial Democracy, 19(1): 185-198.

Durand, J.P. (1999). The diversity of employee relationships. En Teamwork in the automobile industry. Radical change or passing fashion?, Durand, J.P., Stewart, P. y Castillo, J.J. (Eds.) Londres: MacMillan Press.

Durand, J.P., Stewart, P. y Castillo, J.J. (1999) (Eds.). Teamwork in the automobile industry. Radical change or passing fashion?. Londres: MacMillan Press.

Eichner, V. (1991). Organizational concepts in German industry. Bruselas: Comisión Europea, FAST-Monitor.

Ellegard, K. (1995). The creation of a new production system at the Volvo automobile assembly plant in Uddevalla, Sweden. En Enriching production, Sandberg, A. (Ed.). Aldershot: Avebury. 
Engstrom, T. y Medbo, L. (1995). Production system design- A brief summary of some Swedish design efforts. En Enriching production, Sandberg, A. (Ed.). Aldershot: Avebury.

Freyssenet, M. (1998). 'Reflective Production': an alternative to mass production and lean production?. Economic and Industrial Democracy, 19(1): 91-117.

Freyssenet, M. (1999). Transformations in the teamwork at Renault. En Teamwork in the automobile industry. Radical change or passing fashion?, Durand, J.P., Stewart, P. y Castillo, J.J. (Eds.) Londres: MacMillan Press.

Friedmann, G. (1977). La crisis del progreso. Barcelona: Laia.

Gaudemar, J.P. de (1991). El orden en la producción. Madrid: Trotta.

Gerst, D., Hardwig, T., Kuhlmann, M. y Schumann, M. (1999). Group working in the German industry- The case of Mercedes Benz. En Teamwork in the automobile industry. Radical change or passing fashion?, Durand, J.P., Stewart, P. y Castillo, J.J. (Eds.) Londres: MacMillan Press.

Gobierno Vasco -Eusko Jaurlaritza (1994). Clúster de Máquina-Herramienta: Una visión para el futuro. Bilbao: Programa de Competitividad de Euskadi.

Gobierno Vasco -Eusko Jaurlaritza (1992). Programa de Competitividad del Clúster de Máquina-Herramienta. Bilbao (documento confidencial).

Grzyb, G.J. (1981). Decollectivization and recollectivization in the workplace: the impact of technology on informal groups and work culture. Economic and Industrial Democracy, 2(4): 455-482.

Kenney, M. y Florida, R. (1988). Beyond mass production: production and the labour process in Japan. Politics and Society, 16(1): 121-158.

Kern, H. y Schumann, M. (1988). El fin de la división del trabajo. Madrid: Ministerio de Trabajo.

Kidd, P. (Ed.) (1990). Organization, people and technology in European manufacturing. Bruselas: Comisión Europea, FAST-Monitor.

Kissler, I. (1994). Industrial modernization by workers' participation. Economic and Industrial Democracy, 15(2): 179210.

Kruse, W. (1988). Presentación. Sociología del Trabajo, 2: 5-9.

Labit, A. (1999). Group working at Volkswagen: an issue for negotiation between trade unions and management. En Teamwork in the automobile industry. Radical change or passing fashion?, Durand, J.P., Stewart, P. y Castillo, J.J. (Eds.) Londres: MacMillan Press.

Lahera Sánchez, A. (1998). Fábrica y comunidad: Transformación del trabajo e interdisciplinariedad en las Ciencias Sociales del Trabajo. Sociología del Trabajo, 33: 71-102.

(c) Arturo Lahera Sánchez. Publicado en AIBR. Revista de Antropología Iberoamericana, Ed. Electrónica

Vol 1. Num. 3. Agosto-Diciembre 2006. Pp. 428-464 Madrid: Antropólogos Iberoamericanos en Red. ISSN: 1578-9705 
Lahera Sánchez, A. (1999). El diseño de artefactos tecnológicos: sobre la introducción de nuevas tecnologías en la empresa. Sociología del Trabajo, 38: 57-89.

Lahera Sánchez, A. (1999b). La crítica de la economía de mercado en Karl Polanyi: el análisis institucional como pensamiento para la acción. Revista Española de Investigaciones Sociológicas-REIS, 86: 27-54.

Lahera Sánchez, Arturo (2000). La emergencia de nuevos modelos productivos y la participación de los trabajadores: Diseño e implantación de conceptos antropocéntricos de producción en empresas fabricantes de máquinas-herramienta. Tesis doctoral inédita, Departamento de Sociología III, Universidad Complutense de Madrid. Dirigida por Juan José Castillo.

Lahera Sánchez, Arturo (2000b). La emergencia de nuevos modelos productivos: la participación de los trabajadores y la fabricación del consentimiento en la producción. Revista de Dialectología y Tradiciones Populares (CSIC), tomo LV, cuaderno segundo: 9-50.

Lahera Sánchez, Arturo (2001). La participación de los trabajadores en la empresa: ¿hacia la democratización de las relaciones industriales? Una propuesta metodológica de análisis. En Sobre la democracia económica. La democracia en la empresa. Fernández Steinko, A. y Lacalle, D. (Eds.). Barcelona: El Viejo Topo y Fundación de Investigaciones Marxistas.

Lahera Sánchez, Arturo (2003). Gestión participativa de los recursos humanos en empresas fabricantes de máquinas-herramienta: Una evaluación crítica de la participación de los trabajadores. Inguruak, 35: 101-136.

Lahera Sánchez, Arturo (2004). La participación de los trabajadores en la democracia industrial. Madrid: La Catarata.

Lahera Sánchez, A. (2004b). La participación de los trabajadores en la calidad total: nuevos dispositivos disciplinarios de organización del trabajo. Revista Española de Investigaciones Sociológicas-REIS, 106: 63-101.

Lahera Sánchez, Arturo (2005). Enriquecer el factor humano: Paradigmas organizativos y trabajo en grupo. Barcelona: El Viejo Topo y Fundación de Investigaciones Marxistas.

Lahera Sánchez, Arturo (2005b). Mutaciones productivas, trabajo y empleo: ¿Desarrollando la cualificación y las competencias de los recursos humanos?. En Competencias, igualdad de oportunidades y eficacia de la formación continua. Fundación Tripartita para la Formación en el Empleo (Ed.). Madrid: Fundación Tripartita.

Lahera Sánchez, Arturo (2006). Diseño tecnológico y proceso de trabajo: mutaciones organizativas en empresas de ingeniería mecánica. Madrid-Buenos Aires: Miño y Dávila Editores.

Lehner, F. (1991). Anthropocentric Productions Systems. The European response to advanced manufacturing and globalization. Bruselas: Comisión Europea, FAST-Monitor.

Leite, M. de P. (1993). Innovación tecnológica y subjetividad obrera. Sociología del Trabajo, 19: 3-26.

Linhart, D. (1990).¿Qué cambios en la empresa?. Sociología del Trabajo, 11: 25-48.

(C) Arturo Lahera Sánchez. Publicado en AIBR. Revista de Antropología Iberoamericana, Ed. Electrónica

Vol 1. Num. 3. Agosto-Diciembre 2006. Pp. 428-464 Madrid: Antropólogos Iberoamericanos en Red. ISSN: 1578-9705 
Linhart, D. (1997). La modernización de las empresas. Buenos Aires: Asoc. Trabajo y Sociedad.

Linhart, D. (1997b). El trabajo y el empleo en Francia. Algunos elementos del debate científico. Sociología del Trabajo, 31: 15-36.

Marx, K. (1979). El capital. Madrid: Siglo XXI.

Marx, R. y Salerno, M.S. (1999). Teamwork in General Motors Brazil: What is changing in the organisation of work?. En Teamwork in the automobile industry. Radical change or passing fashion?, Durand, J.P., Stewart, P. y Castillo, J.J. (Eds.) Londres: MacMillan Press.

Nilsson, L. (1995). The Uddevalla plant. En Enriching production, Sandberg, A. (Ed.). Aldershot: Avebury.

Novick, M. (1991). Nuevas tecnologías de gestión y acción sindical. Estudios del Trabajo, 1: 77-111.

Rosemberg, N. (1986). Inside the black box: technology and economics. Nueva York: Cambridge Univ. Press.

Sandberg, A. (1993). Volvo human-centred work organization- The end of the road?. New Technology, Work and Employment, 8(2): 83-92.

Sandberg, A. (1995). Enriching production. Aldershot: Avebury.

Sandberg, A. (1998). Good work and productivity. Economic and Industrial Democracy, 19(1): 5-16.

Schumann, M. (1998). New concepts of production and productivity. Economic and Industrial Democracy, 19(1): 1732.

Schumann, M. (1999). El desarrollo del trabajo industrial: nuevas contradicciones. En El trabajo del futuro. Castillo, J.J. (Ed.). Madrid: Editorial Complutense.

Smith, C. (1989). Flexible specialization, automation and mass production. Work, Employment and Society, 3(2): 203220.

SPRI (1994). Informes básicos sectoriales de la Comunidad Autónoma del País Vasco: Máquina-herramienta. Bilbao.

Taylor, F.W. (1914). Declaración ante la United States Commission on Industrial Relations: Efficiency systems and labor. Washington, D.C.

Taylor, F.W. (1925). La dirección de los talleres. Barcelona: Feliu y Susanna.

Taylor, F.W. (1970). Principios de la administación científica. Barcelona: Oikos.

Teiger, C. (1994). El trabajo, ese oscuro objeto de la ergonomía. Sociología del Trabajo, 22: 3-28. 
Terssac, G. de (1996). Autonomía en el trabajo. Madrid: Ministerio de Trabajo.

Thompson, E.P. (1967). Time, work-discipline and industrial capitalism. Past and Present, 38: 56-97.

Troussier, J.F. (1987). Considerations on the collective dimension of work. New Technology, Work and Employment, 2(1): 37-46.

Wobbe, W. (1991). Anthropocentric Production Systems. A strategic issue for Europe. Bruselas: Comisión Europea, FAST-Monitor.

Womack, J.P., Jones, D.T. y Roos, D. (1991). The machine that changed the world. Nueva York: Harper Collins.

Wright, M. y Edwards, P. (1998). Does teamworking work, and if so, why?. Economic and Industrial Democracy, 19(1): 59-90. 